PONTIFÍCIA UNIVERSIDADE CATÓLICA dO RIO dE JANEIRO

\title{
Blockchain e Modelo VRIO: Uma Aborgadem Estratégica Sobre a Geração de Vantagem Competitiva Sustentável da Tecnologia em Empresas no Setor de Supply Chain
}

William de Assis Fonseca dos Santos

Trabalho de Conclusão de Curso

Centro de Ciências Socials - CCS

Departamento de AdMINISTRAÇÃo

Graduação em Administração de Empresas 
Rio de Janeiro, novembro de 2020. 


\section{William de Assis Fonseca dos Santos}

Blockchain e Modelo VRIO: Uma Aborgadem Estratégica Sobre a Geração de Vantagem Competitiva Sustentável da Tecnologia em Empresas no Setor de Supply Chain

Trabalho de Conclusão de Curso

Trabalho de Conclusão de Curso, apresentado ao programa de graduação em Administração da PUC-Rio como requisito parcial para a obtenção do titulo de graduação em Administração. 
Rio de Janeiro, Novembro de 2020. 


\section{Agradecimentos}

À minha mãe, sustentáculo que me deu a vida e lutou, durante toda a sua, para que eu tivesse condições de alcançar o sonho que agora realizo, apesar de todas as dificuldades enfrentadas. Mulher de fibra, abençoada com o nome de Maria: a ti serei grato até o suspiro que me findará. Devo-lhe tudo e serei eternamente grato por me gerar, cuidar e amar. Meu coração é seu. À minha irmã Stefanne, agradeço pela companhia e pelo presente que foi na minha vida: você sempre será minha pequena princesa.

Às professoras Veranise Dubeux, Claudia Duarte Soares, Sylvia Therezinha, Mila Desouzart, Maria Isabel, Eliana Giambiagi e aos professores Marcelo Ghiaroni, Marcelo Piñeiro, Andre Roizman e Martim Francisco, expresso minha eterna gratidão por tudo o que me ensinaram e por me auxiliarem nesta jornada de quatro anos condensados em 67 páginas e um sonho: com suas asas, nada me foi pesado. Meu cientista favorito, Newton, resume: vi mais longe porque estive nos ombros de todos estes gigantes citados aqui.

Professor Martim, obrigado pela sua paciência, sua confiança e sua crença em mim. Sua orientação, suas correções, seu brilhantismo e sua competência me guiaram neste trabalho. Guardo na memória suas aulas, de certo algumas das melhores que tive em toda a graduação. Sua sabedoria é rara, nobre e poderosa.

Agradeço aos contatos na entrevista desta monografia: foram de fundamental importância para meu sucesso neste estudo. Agradeço também aos criadores do ProUni, assim como a cada cidadão brasileiro que financiou minha trajetória nesta graduação: está aqui o resultado de seus investimentos em mim.

Agradeço, acima de tudo, a Deus Pai, ao Nosso Senhor Jesus Cristo e a Mãe Maria. Nos momentos mais difíceis, foram os que estiveram comigo. Deus continua cumprindo com Sua palavra e me dado mais do que mereço. Nada do que ocorreu até aqui ocorreu sem que fosse da vontade d'Ele: somos o que nos permitimos ser, com a grandeza que Ele destinou que tivéssemos. Sou grato por Ele ter me destinado a conquistar a vitória desta monografia. 


\section{Resumo}

Santos, William de Assis Fonseca dos. Blockchain e Modelo VRIO: Uma Aborgadem Estratégica Sobre a Geração de Vantagem Competitiva Sustentável da Tecnologia em Empresas no Setor de Supply Chain. Rio de Janeiro, 2020. Número de páginas p.56. Trabalho de Conclusão de Curso Departamento de Administração. Pontifícia Universidade Católica do Rio de Janeiro.

O objetivo deste Trabalho de Conclusão de Curso foi o de, à luz da teoria sobre Visão Baseada em Recursos e utilizando o modelo VRIO, analisar se o recurso Blockchain é capaz de gerar vantagem competitiva sustentável para as empresas quando usado no setor de supply chain. Para tal, foi aplicada uma pesquisa qualitativa, contendo 10 questões, com oito entrevistas, de cinco empresas distintas, prestadoras do serviço de Blockchain para cadeias de suprimentos e empresas ligadas diretamente a operação da cadeia de abastecimento. Foi analisado se o Blockchain seria um recurso valioso, raro, imitável e organizável. Chegou-se a conclusão, em termos gerais, que o Blockchain não oferece vantagem competitiva sustentável nesta área, embora possa ser classificado como um recurso de paridade competitiva.

Palavras- chave

Blockchain, Supply Chain, Logística, VBR, RBV, VRIO, Administração

\section{Abstract}

Santos, William de Assis Fonseca dos. Blockchain and VRIO Model: A Strategic Approach on Generating Sustainable Competitive Advantage of Technology in Companies in the Supply Chain Sector. Rio de Janeiro, 2020. Número de páginas p.56. Trabalho de Conclusão de Curso - Departamento de Administração. Pontifícia Universidade Católica do Rio de Janeiro.

The goal of this paper was to analyze whether the Blockchain resources can generate sustainable competitive advantage when applied in companies in the supply chain sector, considering the theory about Resource Based View and VRIO model. To this end, a qualitative survey was applied, containing 10 questions, with eight interviews, from five different companies, which are Blockchain service providers for supply chains and companies directly linked to supply chain operation. It was analyzed whether Blockchain would be a valuable, rare, imitable 
and organizable resource. It was concluded, in general terms, that Blockchain does not offer a sustainable competitive advantage in this area, although it can be classified as a resource of competitive parity.

\section{Key-words}

Blockchain, Logistics, Supply Chain, RBV, VRIO, Business Management 


\section{Sumário}

1. O problema 10

1.1. Introdução 10

1.2. Objetivo Final 14

1.3. Objetivos Intermediários $\quad 15$

1.4. Delimitação do Estudo $\quad 15$

1.5. Relevância do Estudo 16

2. Referencial Teórico 18

2.1. Blockchain: o que é e perspectiva de uso no mercado brasileiro 18

2.2. Processos de inovação para geração de valor atrelados à cooperação e competitividade 20

2.3. Conceituação de Logística, Supply Chain e uso do Blockchain na cadeia de suprimento 22

2.4. Visão Baseada em Recursos e modelo VRIO 25

3. Metodologia de Pesquisa 29

3.1 Tipo de Pesquisa $\quad 29$

3.2 Universo, Amostra e Seleção de Sujeitos 30

3.3 O Procedimento de Coleta de Dados 33

3.4 Tratamento de Dados 33

3.5 Limitações do Estudo 34

4. Análise dos Resultados 35

4.1 Área, função e experiência do entrevistado 35

4.2 Uso do Blockchain na operação 39

4.3 Feedbacks e projeção de investimentos $\quad 47$

4.4 Estratégia no setor de Supply Chain 49

5. Conclusão 55

5.1 Recomendações para novos estudos 66

$\begin{array}{ll}\text { 6. Bibliografia } & 68\end{array}$

Apêndice: Roteiros usados nas entrevistas $\quad 75$ 


\section{Lista de Figuras}

Figura 1 - Funcionamento do Blockchain 19

$\begin{array}{ll}\text { Figura } 2 \text { - A Cadeia de valor de inovação } & 21\end{array}$

Figura 3 - Comparação de confiança entre componentes descentralizados (Blockchain) e centralizados 23

Figura 4 - Modelo VRIO 28

\section{Lista de Tabelas}

Tabela 1 - Perfil dos profissionais entrevistados 32

Tabela 2 - Modelo VRIO e perguntas do questionário 57

Tabela 3 - Análise VRIO: Hélio Mosquim 58

Tabela 4 - Análise VRIO: Leonardo Alexander 59

Tabela 5 - Análise VRIO: Carlos Lessandro 60

Tabela 6 - Análise VRIO: Carlos Henrique 61

Tabela 7 - Análise VRIO: Reider Arnaud 62

Tabela 8 - Análise VRIO: Eric Rossati 63

Tabela 9 - Análise VRIO: Resultado geral 64 


\section{O problema}

\subsection{Introdução}

As tecnologias disruptivas despontam como fatores-chave para 0 aumento da competitividade e da eficiência dos processos empresariais neste começo de século XXI, bem como tornam-se elementos primordiais no auxílio da tomada de decisões estratégicas por parte dos gestores do milênio em trânsito. Após os avanços conquistados pela Terceira Revolução Industrial, iniciada nos anos 60 do século passado, e da consequente criação de um novo paradigma para o crescimento tecnológico das indústrias - calcado notadamente nos campos da biogenética, robótica, engenharia de materiais, exploração espacial e com os modelos de fabricação assistida por computador CAD/CAM (ComputerAided Design e Computer-Aided Manufacturing - em português Desenho Assistido por Computador e Manufatura Assistida por Computador) (FINKELSTEIN; NEWMAN, 1984) -, a trajetória traçada pela necessidade de fluxos de informações e de produção cada vez mais globalizados apontou para o advento da Quarta Revolução Industrial, também conhecida como Indústria 4.0.

Esta quarta fase - que não demonstra precedentes quanto ao seu nível de escala, escopo, complexidade e velocidade em relação às anteriores - irá conectar bilhões de pessoas por meio de diversos dispositivos que, por sua vez, terão suas funcionalidades gerenciadas por tecnologias como Inteligência Artificial, Internet das Coisas, Nanotecnologia e Computação Quântica (SCHWAB, 2016).

Ao lado destas novas possibilidades tecnológicas emerge 0 Blockchain: descrita como um "sistema de caixa eletrônico peer-to-peer", esta nova ferramenta abarca um mecanismo computacional criptografado que permite maior segurança, transparência, descentralização e 
gerenciamento de dados particulares envolvendo transações comerciais entre duas partes, eliminando a necessidade de um terceiro ator como intermediário dentro do processo. Tendo como uma de suas finalidades o armazenamento de informações similar ao de um livro-razão (ledger) gerando um registro virtualmente impossível de ser sabotado -, o Blockchain visa também fornecer provas do passo-a-passo destas transações, incluindo data e hora (NAKAMOTO, 2008).

Maior economia da América Latina, nona maior do mundo e apresentando um PIB (Produto Interno Bruto) de \$1.85 trilhões em 2019, de acordo com dados do Banco Mundial (WORLD BANK, 2019), o Brasil entra na rota de potenciais países onde o Blockchain deve ser empregado em maior escala. Estudo realizado pela companhia Deloitte (PAWCZUK et al., 2020), entre feveiro e março de 2020, em 14 países, confirma esta projeção para o mercado nacional: dos 50 executivos brasileiros entrevistados pela consultoria, 64\% afirmaram ter planos para investir valores entre US\$ 1 milhão a US\$ 10 milhões até 2021 na tecnologia, superando a média de $54 \%$ de outros executivos consultados mundialmente.

Mensurar a capacidade disruptiva do Blockchain frente às atuais ferramentas digitais requer entender que inovações ele pode proporcionar em seus potenciais fins, de modo a justificar os investimentos citados anteriormente no estudo. Seu uso está ligado, em grande parte, à constante busca das empresas por novos métodos dentro de seus processos produtivos ou de entrega de serviços, de modo a tornar suas operações mais eficientes e o resultado das mesmas mais satisfatório para seus stakeholders. Ao enfrentarem um ambiente de concorrência complexo, originado das cada vez mais rápidas mudanças de tecnologias, bem como da troca de informações dinâmicas e dos novos tipos de modelos de negócios (PILAV-VELIĆ; MARJANOVIC, 2016), as organizações depreendem que os procedimentos de inovação serão a base para criação de valor e diferenciação no mercado: novas estruturas, com dados mais precisos e melhores produtos, surgem destes procedimentos (KIRCHMER, 2008). 
A aplicabilidade do Blockchain, bem como a consequente inovação gerada pelo seu potencial disruptivo, encontra terreno fértil em muitas frentes quando se trata da geração de valor dentro das corporações. Um dos campos que mais tem atraído a atenção de programadores e gestores que trabalham com a tecnologia é o da logística, justamente pela capacidade da ferramenta em inovar os processos ligados ao setor: melhorias nas análises em tempo real de dados comerciais globais e nas atividades de importadores, exportadores, companhias de transporte terrestre, marítimo e aéreo, de clientes e de terminais, de modo a especificar a maneira mais eficiente de transportar bens por pontos de friç̧ão, são alguns dos ganhos proporcionados pela implementação deste recurso digital. A eliminação das diversas ineficiências dos fretes tradicionais e o aperfeiçoamento de serviços logísticos como agendamento automatizado, consolidação de entregas de múltiplos remetentes, transporte sob demanda e análise de dados das operadoras, são objetivos nos quais a logística também busca maior eficência (CORREIA; TIPPING; BAUMEISTER; KLETZEL; KAUSCHKE, 2019).

Tratar dos avanços tecnológicos no campo da logística, atrelados ao Blockchain, é também tratar, complementando com os processos de inbound, de quais benefícios esta tecnologia trará para o gerenciamento das cadeias de suprimentos, área que tem atraído diversos investimentos dos gestores de $\mathrm{Tl}$ ao redor do mundo, face à crescente demanda por processos de entrega de produtos/serviços cada vez mais interligados globalmente. Construída por fornecedores, fabricantes, revendedores e operadores logísticos, a rede de supply chain tem, como definição quanto à sua gestão, a articulação estratégica e sistemática das tradicionais funções de negócios e as táticas entre essas funções dentro de uma determinada empresa, bem como entre os negócios na cadeia de abastecimento, para fins de melhoraria de desempenho de longo prazo dos agentes e da cadeia como um todo (MENTZER et al., 2001). Ao ser atrelado à gestão da cadeia de suprimentos, o Blockchain pode proporcionar maior transparência às transações das fases de inbound e outbound: utilizada como ferramenta para processos de inovação, a tecnologia traz consigo vantagens relativas, de compatibilidade, de ganhos em situações de 
complexibilidade e experimentabilidade, além de possibilitar maiores pontos de observação dentro das cadeias (BADZAR, 2016). A transparência fornecida pelo Blockchain também assevera o pleno cumprimento das cláusulas de contrato celebradas pelos fornecedores envolvidos na rede de supply chain (IMERI; KHADRAOUI; AGOULMINE 2018).

Entender as contribuições mais relevantes da utilização do Blockchain nos processos da cadeia de suprimentos e em sua gestão, de modo a elencá-las como fatores de competição no mercado, passa por analisar, primordialmente, que visão estratégica as firmas possuem sobre seus processos dentro das cadeias das quais fazem parte. Em se tratando do diagnóstico estratégico que leva em consideração os recursos e competências disponíveis pelas empresas, desponta como concepção pertinente a ser empregada a conhecida Visão Baseada em Recursos. Operando sob tal prisma, este estudo visa fornecer uma investigação a respeito da confirmação - ou não - de que o recurso estratégico por trás do manuseio do Blockchain é heterogêneo entre as firmas que atuam no setor de supply chain, bem como se este mesmo recurso é - ou não - distribuído de forma perficiente por estas instituições, gerando, ao fim e ao cabo, uma vantagem competitiva no longo prazo para as mesmas. Quanto à categorização do recurso, esta monografia focará apenas na identificação do pertencente ao capital intangível das empresas, qual seja, da tecnologia (BARNEY; JAY, 1991).

Tratar de tais recursos é, em última instância, inferir a possibilidade deles proporcionarem criação de valor por uma empresa, de modo a enxergar a impossibilidade de outros players executarem esta mesma criação. Em não sendo possível esta execução, cria-se o cenário da vantagem competitiva sustentável, no qual os recursos são elencados como fundamentais por meio dos atributos de Valor, Raridade, Imitabilidade e Organização, tal como preconiza o modelo VRIO. Ao relacionar estas variáveis contidas no modelo VRIO com o uso do Blockchain nas operações da cadeia de suprimentos, esta monografia busca a compreensão sobre a possibilidade da tecnologia ser um recurso 
valioso, exclusivo, raro e gerador de valor sustentável (BARNEY; JAY, 1991).

Embora promissora e potencialmente uma das tecnologias mais disruptivas da Indústria 4.0, o Blockchain também enfrenta percalços quanto a sua implementação e popularização: adversidades quanto à sua escalabilidade, à sua taxa de transferência (velocidade de transmissão de dados), ao seu controle de acesso e a recuperação de dados são alguns dos gargalos técnicos apresentados dentro das cadeias de suprimentos (WU et al, 2019). Altos custos de transição entre ecossistemas, dificuldade de aprendizado, mão-de-obra qualificada em falta e os impactos econômicos da atual pandemia na economia moldam também este cenário de dificuldades que o Blockchain enfrentará.

Considerando o contexto, o presente estudo visa responder se é possível inferir que o uso do Blockchain cria vantagem competitiva sustentável para as empresas pela sua aplicação na área de Supply Chain, observando-se 0 atual estado-da-arte da tecnologia, as oportunidades e os obstáculos do mercado.

Em busca de respostas para esta indagação e de um maior entendimento quanto à maturidade das aplicações de Blockhain em voga nas corporações, uma pesquisa qualitativa foi produzida e aplicada a executivos, gestores e empreendedores brasileiros que usam este dispositivo digital em processos de cadeias de suprimentos. A investigação realizada visou mapear o quê de mais inovador e atual está sendo implementando nas empresas no que tange ao incremento do Blockchain em fluxos de processos em supply chain, indicando a geração de valor e o estado de competitividade das mesmas.

\subsection{Objetivo Final}

A finalidade a qual se propõe a monografia em questão é a de responder quais são as aplicações mais promissoras e que abrangem a utilização da tecnologia Blockchain nos processos de cadeias de suprimentos e se elas, de fato, conduzem a um potencial de vantagem competitiva sustentável. 


\subsection{Objetivos Intermediários}

Como passos interpostos para o objetivo final, foram percorridos os seguintes pontos:

- Compreender os motivos pelos quais a tecnologia Blockchain foi escolhida para ser implementada nos processos das cadeias de suprimentos;

- Enxergar quais oportunidades foram percebidas pelas empresas dentro destes processos e de que forma elas puderam ser concretizadas em geração de valor para as corporações (se, em tais oportunidades, houve interface do Blockchain, por exemplo, com sistemas de informação logísticos como WMS, TMS, ERP e MRP);

- Elencar ganhos de produtividade e competitividade nos processos da cadeia de abastecimento;

\subsection{Delimitação do Estudo}

Dada a dificuldade da obtenção de dados considerados confidenciais por parte das empresas que recebem os serviços de Blockchain aplicados aos processos das cadeias de suprimentos (clientes finais), este estudo foi construído levando-se em consideração, também, o viés das organizações que fornecem a tecnologia Blockchain para estas empresas, ou seja, pelo lado do prestador do serviço: tal condição não implica, contudo, a impossibilidade das empresas fornecedoras do serviço terem desenvolvido modelos de negócios com a aplicação.

Este trabalho delimitou-se à entender, sob a ótica da visão estratégica utilizada em administração, quais contribuições o Blockchain é capaz de proporcionar quando empregado como uma ferramenta de gestão dentro da cadeia de suprimentos, contando com entrevistas de gestores e empresários que atuam com serviços empregados no Brasil (tomando em consideração, também, o caráter global das transações destas cadeias). A restrição a aspectos de gerenciamento e a utilização estratégica da tecnologia nos processos de inbound e outbound se faz importante para 
formar o contexto administrativo do tema, evitando análises mais profundas a respeito de argumentos técnicos e operacionais sobre o Blockchain.

\subsection{Relevância do Estudo}

As ineficiências e gargalos apresentados nas cadeias de abastecimento, tais como atrasos de entrega, custos dobrados, falta de visibilidade dos processos logísticos como um todo, erros humanos, cobranças de taxas e cancelamentos (IRANNEZHAD, 2020), sugerem que novas metodologias e aplicações sejam utilizadas a fim de que tais problemas sejam solucionados. Em um ambiente cada vez mais complexo, instável, competitivo e que demanda soluções rápidas, seguras e numa escala de volumes de dados massivos, as tecnologias disruptivas e, em especial, o Blockchain, despontam como fatores de inovação e geração de valor para as organizações envolvidas com serviços de suprimentos. Tal conjuntura abre espaço para que investimentos no setor cresçam, ampliando a oferta de trabalho no mercado e entregando produtos/soluções de maior valor agregado e de maior satisfação para os consumidores.

Estudos como este podem auxiliar na construção de uma visão mais pragmática a respeito do papel que o Blockchain desempenha como fator de diferenciação e inovação nas cadeias de suprimentos, bem como demonstrar uma fotografia mais real do atual uso e das atuais condições de aplicabilidade da tecnologia no que tange às atividades de abastecimento, especialmente após a crise ocasionada pelo novo coronavírus. Com um panorama mais recente do mercado e analisando as oportunidades e problemas que emergem de uma perturbação nunca antes vivenciada pela geração de novos administradores (nascida nos anos 1980 em diante) - qual seja, a pandemia - e, quiçá, de gerações de administradores pós-quebra da Bolsa de 1929 e pós-Segunda Guerra Mundial, este trabalho de conclusão de curso pode proporcionar uma nova leitura sobre o uso de tecnologias da Quarta Revolução Industrial no mercado de suprimentos do país, levando em conta que, a entrada desta segunda década, deste segundo milênio, apontará particularidades para 0 
mundo dos negócios que talvez nenhuma outra década da história tenha apontado. Responder ao objetivo desta pesquisa é também oferecer à sociedade e aos profissionais da área de cadeia de suprimentos um novo olhar sobre as operações do setor em meio à e no pós-pandemia. 


\section{Referencial Teórico}

Esta monografia tem seu referencial teórico composto por quatro estruturas: (1) definição da tecnologia Blockchain, situando as perspectivas de sua utilização no mercado brasileiro - interligado com as cadeias de serviços globais -; (2) identificação de processos de inovação desenvolvidos por empresas e relacionados com criação de valor, cooperação entre parceiros e competitividade; (3) conceituação de logística, supply chain e exemplos do uso do Blockchain na cadeia de abastecimento e (4) descrição da ferramenta de estratégia de Visão Baseada em Recursos, apresentando o modelo VRIO e sua aplicabilidade no estudo.

\subsection{Blockchain: o que é e perspectiva de uso no mercado brasileiro}

A tecnologia Blockchain popularizou-se por conta de sua aplicação em transações financeiras envolvendo as chamadas criptomoedas. Voltada para a implementação no comércio digital, a ferramenta ganhou destaque devido à sua capacidade de estabelecer altos padrões de confiabilidade em processos computacionais, bem como pelo fato de abrir mão de intermediadores nestes processos. A tecnologia surge em um contexto no qual "é necessário um sistema de pagamento eletrônico baseado em prova criptográfica, permitindo que duas partes dispostas negociem diretamente" (NAKAMOTO, 2008). Tal sistema, como definido por ZHENG et al (2017), tem em sua concepção a salvaguarda de negociações comerciais em uma base digital:

Blockchain é uma solução de banco de dados distribuída que mantém uma lista crescente de registros de dados que são confirmados pelos nós participantes dela. Os dados são registrados em um livro-razão público, incluindo informações de todas as transações já concluídas. Blockchain é uma solução descentralizada que não requer nenhuma organização terceirizada 
Esta base tem seu alicerce na Tecnologia de Registro Distribuido (Distributed Ledger Technology - DLT, em inglês), um banco de dados que interliga diversos dispositivos por meio de uma rede descentralizada (WALPORT; MGCSA et al, 2016), possibilitando aos participantes de determinada negociação o acesso a um registro (livro) aberto compartilhado. Este registro, por sua vez, aprovisiona a solução para a questão de determinar processos confiáveis em ambientes não-seguros sem a dependência de terceiros agentes entre os integrantes desta negociação (ØLNES; UBACHT; JANSSEN, 2017). A DLT permite ao Blockchain atingir um consenso nas transações com ativos digitais, sejam estas transações retroativas ou realizadas em tempo real, além do acesso as mesmas em qualquer ponto no futuro, asseverando a privacidade dos agentes envolvidos, bem como dos ativos transacionados. Por meio da $D L T$, o Blockchain alcança dois importantes pontos de seu funcionamento: o consenso e o anonimato dos processos performados por ele. Destaca-se também que, uma vez digitalizadas as informações destes processos, aquelas jamais poderão ser excluídas (CROSBY et al., 2016)

Figura 1 - Funcionamento do Blockchain

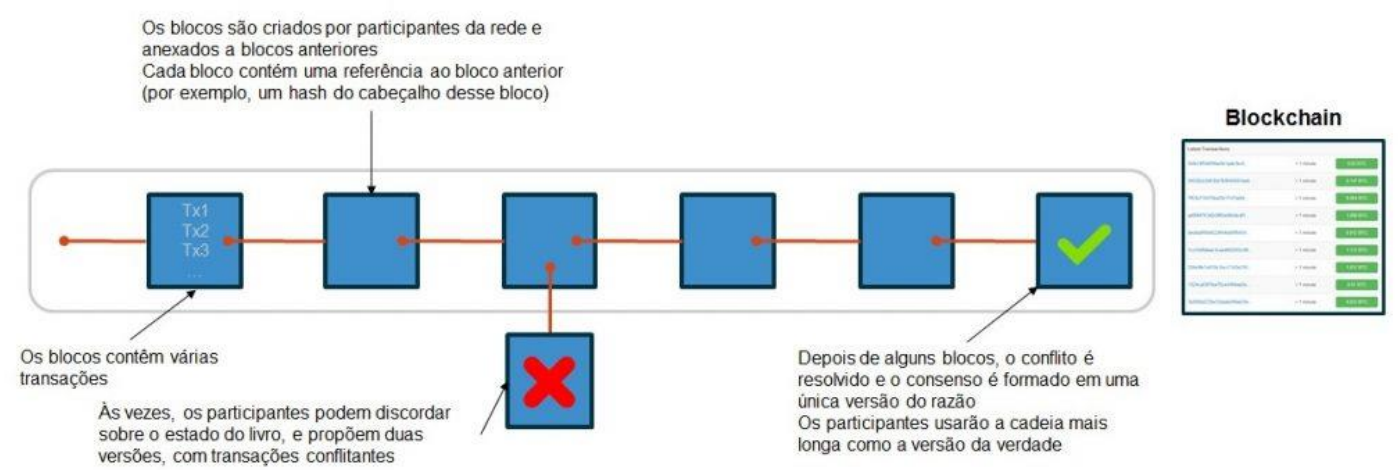

Fonte: Blog Accenture/Estadão, 2017

Os benefícios da implementação do Blockchain citados - e demonstrados na Figura 1 - justificam a tendência da adoção do mesmo nas cadeias globais, como comprova estudo realizado pela Deloitte no início do ano de 2020 (PAWCZUK et al., 2020). Ao contactar executivos no 
mundo inteiro sobre a possibilidade do emprego da ferramenta, a companhia apontou alguns países que planejam investir de forma constante no Blockchain em suas operações, tais como o Brasil: embora não tenha citado a porcentagem exata sobre os brasileiros, a publicação assinala que o país está acima da média de $88 \%$ dos entrevistados de outros países que creêm que a ferramenta será escalável. Uma das conclusões trazidas pelo artigo é a de que, para os executivos $C$-level, o Blockchain participará das estratégias de inovação de suas empresas no curto prazo, consolidando a utilização do mesmo (a consultoria ressalta, contudo, que é necessário analisar os impactos da atual pandemia do COVID-19 para atestar as projeções inicialmente indicadas) (PAWCZUK et al., 2020). Tais esforços para a implementação da tecnologia em território brasileiro puderam ser visualizados em 2018, com a iniciativa do Banco Santander em oferecer o serviço de transferências internacionais One Pay FXe a do Banco Itaú, na integração de seus processos internos envolvendo registros de derivativos (AQUINO, 2019), além da ocorrência, em 2019, da estreia da emissão de debêntures via Blockchain (GREGORIO, 2020) por meio da gestora Piemonte. Em se tratando de oportunidades globais, o Fórum Econômico Mundial (WORLD ECONOMIC FORUM, 2015) projetou, em 2015, que a tecnologia será responsável por $10 \%$ do PIB produzido em todo o planeta no ano de 2027, atestando o imenso mercado a ser explorado por este mecanismo ao longo da década que se inicia.

\subsection{Processos de inovação para geração de valor atrelados à cooperação e competitividade}

O ambiente de negócios que caracteriza as empresas inseridas nos mercados globais de produtos e serviços no século XXI é também composto, em termos de competitividade, pela incessante inquirição de processos de inovação voltados para a maximização e/ou criação de valor dentro das organizações, muitos deles suportados por avançadas ferramentas tecnológicas - como o Blockchain, por exemplo -, potencialmente capazes de gerar diferenciações a ponto de possibilitarem o também surgimento de modelos disruptivos. Tais processos, ao estarem 
inseridos dentro de uma cadeia de valor, invariavelmente seguem três estágios no que tange à gestão do método de inovação (BIANCOLINO; MACCARI; PEREIRA, 2013), elencados como sendo os de (1) Geração de ideias, (2) Conversão e (3) Difusão (HANSEN; BIRKINSHAW, 2007), como retratado na Figura 2. A ideia de inovação como importante fator de geração de valor é corroborada pelo fato dela ser "arriscada, impossível para a maioria dos produtores" (SCHUMPETER, 1997).

Figura 2 - A cadeia de valor de inovação

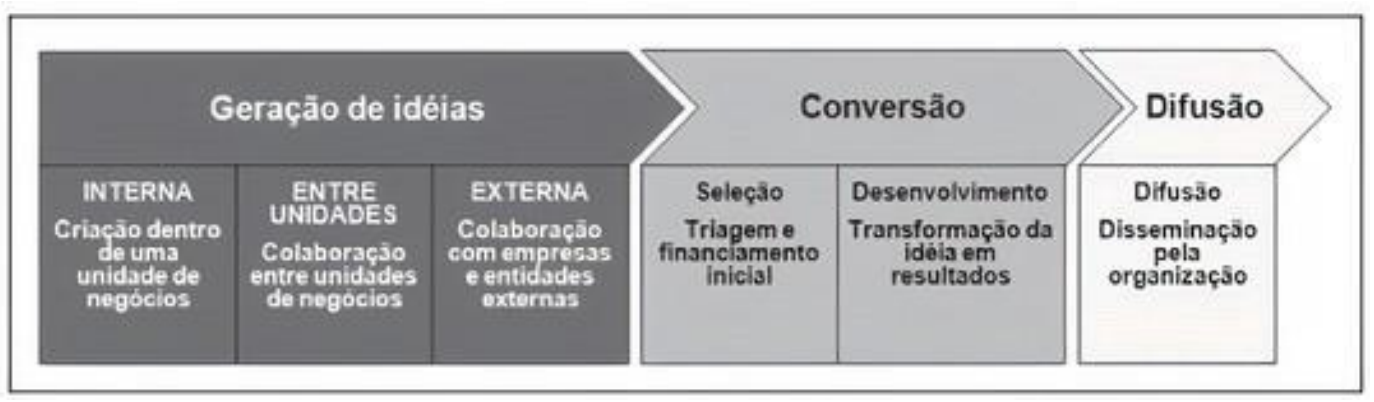

Fonte: Hansen e Birkinshaw (2007). Adaptado.

Faz-se importante salientar, então, em qual conjuntura a inovação pode traduzir-se em um novo valor criado pelas companhias: baseada em como ocorre sua evolução (LEE; OLSON, 2010), quatro etapas podem ser elencadas, entre as quais estão a Inovação 1.0, 2.0, 3.0 e 4.0 (LEE; TRIMI, 2018). Na primeira (LEE et al., 2012), a inovação fica circunscrita aos estudos desenvolvidos pela área de Pesquisa e Desenvolvimento (P\&D) das próprias organizações, resultando em melhorias de suas competências-chave: como exemplo de empresas desta etapa estão listadas a Procter \& Gamble e a NASA; Já na segunda (TAPSCOTT, 2008), entra em cena a colaboração das corporações com fontes externas, que fazem parte da cadeia de valor: nesta modalidade encaixam-se Apple, Boeing e Dell; na Inovação 3.0 (CHESBROUGH, 2003), as organizações contam com inovações advindas de esforços tanto internos quanto do público externo: são exemplos empresas como NineSigma e Yet2.com. Por fim, na quarta etapa (GOBBLE, 2014, GOVINDARAJAN, 2016, LEE ET AL., 2012, RAMASWAMY; OZCAN, 2014), há a metodologia de co-inovação, que interliga uma série de áreas e parceiros, tais como P\&D, tecnologias 
de código aberto, criação simultânea com clientes e outras organizações, de modo a consolidar um ecossistema maduro para a geração de valor por meio das inovações desenvolvidas. A importância da inovação, em última instância - e atrelada à contribuição dada pelo aumento de produtividade , reflete também o nível de competitividade que as companhias apresentam em seus setores: a combinação de forças entre as atividades internas de P\&D e as atividades de inovação, geradas por meio da cooperação tecnológica entre universidades e firmas, são aspectos que influenciam diretamente no arranjo competitivo dos negócios (OECD, 1992, SOLLEIRO, 2005).

Ao fazer parte dos processos mais comuns que compõem a cadeia de valor de inovação, o Blockchain oferece a perspectiva de acompanhamento em tempo real do funcionamento de contratos inteligentes, auxiliando na prevenção de tentativas de manipulações dos registros efetuados; performa suas atividades sem a necessidade de bancos ou governos controlando seu uso, evitando regulações, burocracias e intervenções de terceiras-partes; aumenta a velocidade de processamento das transações e, por fim, concede robustez e segurança no armazenamento de dados em um maior número de nós que compõem os blocos de dados dentro do Blockchain (MORABITO, 2017).

\subsection{Conceituação de Logística, Supply Chain e uso do Blockchain na cadeia de suprimento}

Embora costumeiramente relacionado ao mercado de criptomoedas e a transações financeiras digitais, o Blockchain tem obtido notoriedade em diversos outros campos, entre eles o de supply chain, incluindo logística: sua adoção nestas áreas tem visado enfrentar diversos gargalos operacionais atrelados a visibilidade e transparência de ações dentro das redes de abastecimento, bem como no acompanhamento de indicadores de performance e protocolos de transportes, adversidades estas geradoras de disputas entre os agentes pertencentes as redes de fluxos logísticos e de suprimentos (WILLIAMS, 2015). Neste sentido, a tecnologia desponta como promissora para os operadores logísticos e da cadeia de 
suprimentos, propiciando soluções efetivas para os entraves relacionados à transparência e segurança das operações, de modo a otimizar o rastreio de bens - da origem até o consumidor final - e a garantir o cumprimento das cláusulas contratuais envolvidas na logística de transporte (SIVULA; SHAMSUZZOHA; HELO, 2018). O Blockchain tem ainda suas funções complementadas pela melhoria operacional quanto à previsão e otimização das atividades logísticas e de supply chain (LIEBER, 2017), gerando maior confiança para os stakeholders presentes na negociação, como apresentado na Figura 3:

Figura 3 - Comparação de confiança entre componentes descentralizados (Blockchain) e centralizados

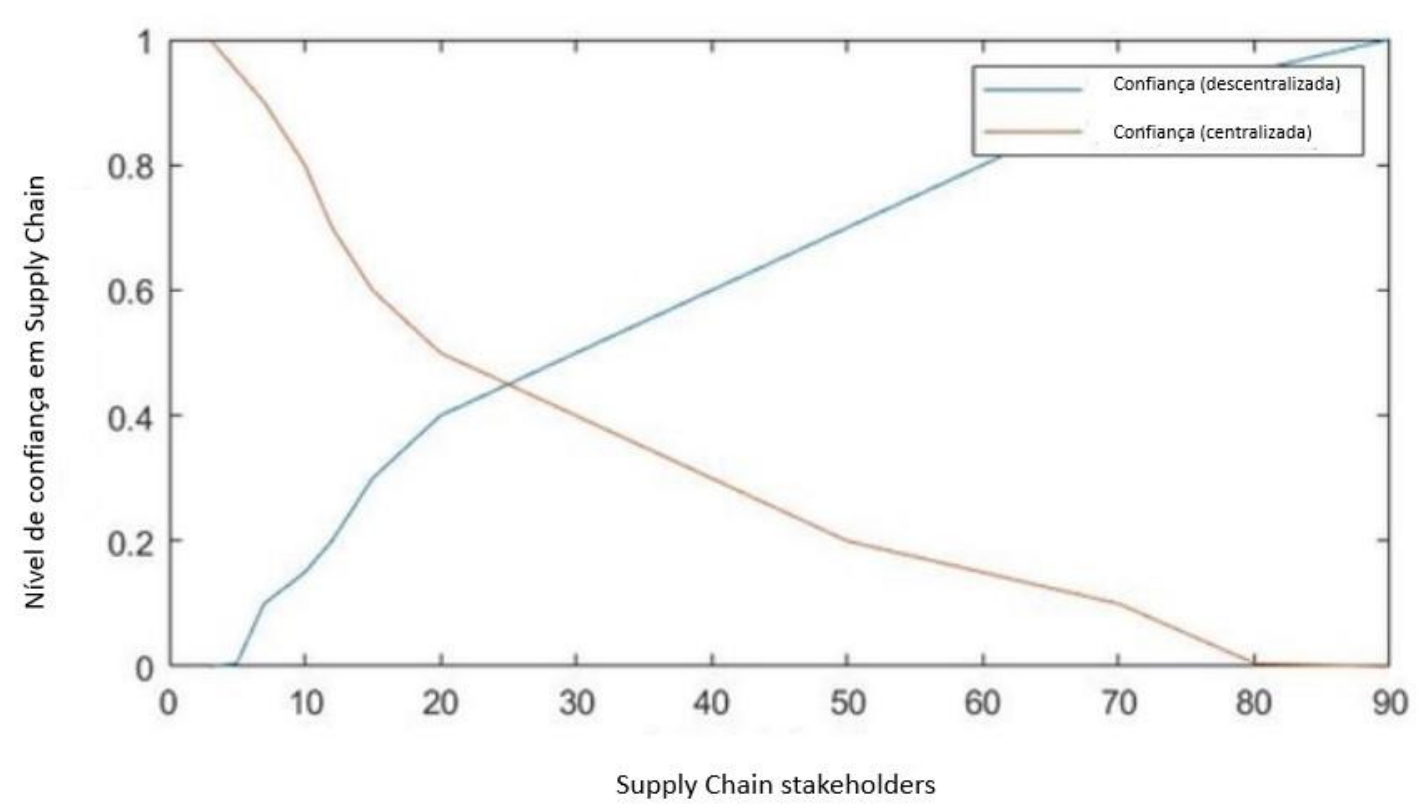

Fonte: IMERI et al, (2019)

Para fins de conceituação, vale salientar que, de acordo com o Council of Supply Chain Management Professional, a logística pode ser definida como:

[P]arte do Gerenciamento da Cadeia de Abastecimento que planeja, implementa e controla o fluxo e armazenamento eficiente $e$ econômico de matérias-primas, materiais semi-acabados $e$ produtos acabados, bem como as informações a eles relativas, 
desde o ponto de origem até o ponto de consumo, com o propósito de atender às exigências dos clientes (CARVALHO, José 2002, p. 31).

E que, supply chain, conforme Kozlenkova (2015), é descrito como sendo:

\begin{abstract}
Sistema de organizações, pessoas, atividades, informação e recursos envolvidos no fornecimento de produtos ou serviços ao consumidor, envolvendo a transformação de recursos naturais, matérias-primas e componentes em um produto finalizado a ser entregue ao consumidor final (KOZLENKOVA, Irina V. et al, 2015).
\end{abstract}

Em relação às atividades, a logística subdivide-se nas principais, que versam sobre transportes, gestão de estoques e processamento de pedidos, e nas secundárias, que dão conta de processos de armazenagem, manuseio de materiais, embalagens, compras, gestão de produtos e sistemas de informação (CARVALHO, 2002). Já a rede de supply chain, de acordo com o Fórum Global de Supply Chain, apresenta um modelo composto por oito processos-chave, todos eles dirigidos por equipes integradas inferfuncionalmente entre as áreas de logística, produção, compras, finanças, marketing e pesquisa e desenvolvimento e que interagem com clientes e fornecedores. Dentro deste modelo, os procedimentos de gestão de relacionamento com os clientes e gestão de relacionamento com os fornecedores são tomados como fatores críticos para o bom funcionamento da cadeia de suprimentos (LAMBERT et al, 1998).

Levando-se em consideração a abrangência destas áreas e o espaço para o crescimento da utilização do Blockchain em fluxos de processos na cadeia de suprimentos no Brasil, já é possível notar iniciativas que comprovam a escalabilidade, as melhorias e as inovações que a ferramenta é capaz de proporcionar ao mercado nacional - além, é claro, das conexões com os fluxos globais - : entre os projetos aplicados, encontram-se a parceria entre IBM, BRF e Carrefour (COSTA, 2017) (visando o impedimento de fraudes na cadeia produtiva e de comércio de 
alimentos, - projeto conhecido como IBM Food Trust); o primeiro hackthon da Intelipost, também em conjunto com a IBM (INTELIPOST, 2017) (apresentando soluções para serviços de gerenciamento de fretes, auditoria de faturas e rastreamento de cargas); a primeira edição do Logistics Tech Challenge (ABRALOG, 2018), evento envolvendo a Abralog (Associação Brasileira de Logística), a Intelipost e a Oracle (cujo objetivo foi o de demonstrar o ganho de tempo no rastreamento de cargas entre vários agentes - processo que, sem o Blockchain, levaria meses e que, com a tecnologia, levou apenas dois dias) e o consórcio entre Maersk e IBM (IBM, 2019), que gerou a solução TradeLens (plataforma digital que visa otimizar os fluxos de documentos comerciais em diversos portos do país, digitalizando cerca de 10 milhões de eventos por semana). Corroborando com as soluções anteriormente citadas, estudo desenvolvido pela consultoria PwC (PWC, 2019) aponta que, entre as cinco forças que despontarão nos próximos anos como tendências para a transformação da área de transportes e logística, está a mudança de processos baseada em softwares - que, por sua vez, abarcam o uso do Blockchain: setores como o de postagem, comércio eletrônico, gestão da cadeia de suprimentos, infraestrutura de transporte e armazenamento, ferrovias, transporte marítimo e de interior, transporte rodoviário e frete e encaminhamento serão os mais beneficiados pelo uso da ferramenta digital, que otimizará os serviços de automação de pagamentos, rastreamento, digitalização e automação de fluxo de documentações, automação de atividades de armazenamento e autenticação de produtos.

\subsection{Visão Baseada em Recursos e modelo VRIO}

Os ganhos gerados pela utilização do Blockchain nas atividades pertencentes às cadeias de supply chain não se restringem somente às operações performadas com o apoio da tecnologia. Como exposto no tópico sobre processos de inovação, o uso da ferramenta surge como recurso a ser explorado dentro de uma cadeia de valor, podendo propiciar condições para que os prestadores de serviços criem, em última instância, modelos de negócios disruptivos, maior eficiência e, até mesmo, vantagens 
competitivas sustentáveis. Muitas são as possibilidades para melhor gerir e analisar o funcionamento estratégico desta tecnologia e, entre elas, encontramos na administração a literatura sobre a Visão Baseada em Recursos (VBR em português ou RBV - Resource-based View, em inglês).

Postos como componentes essenciais para as firmas, os recursos por elas utilizados são capazes de contribuir para o surgimento de vantagens de uma empresa sobre outra: para Barney (1991), entender como ou porque tais recursos contribuem de tal modo é a chave que embasa tanto a teoria sobre a Visão Baseada em Recursos quanto a capacidade de influenciar decisões sobre a gestão estratégica. Este paradigma segue a referência de Wernerfelt (1984), cuja interpretação indica que as organizações adotam estratégias de atuação no mercado e, consequentemente, atingem vantagens competitivas, ao estudarem como são empregados os seus recursos. O cerne da teoria também pode ser definido pela relação de causa existente entre as vantagens competitivas sustentáveis e o diagnóstico sobre o recurso ser escasso ou estar disponível (PFEFFER; SALANCIK,1978; ULRICH; BARNEY, 1984). Ainda sobre os recursos, a literatura põe em evidência a contribuição pioneira de Penrose (1959) a respeito deles dentro da teoria do crescimento da firma, preconizando que o conjunto dos mesmos, elencados dentro da visão administrativa das empresas, é responsável pela sobrevivência dos empreendimentos.

Meyer (1991) reforça o entendimento de Bayer sobre o tema ao descrever a estrutura em que este considera os recursos como passíveis de serem valiosos, raros, difíceis de serem imitados e não-substituíveis, condições necessárias para a manifestação das vantagens competitivas. Barney (1991) continua sua sustentação sobre a importância dos recursos e dos produtos ao afirmar que os primeiros são distrubuídos de forma heterogênea entre as firmas, enquanto que os produtos por eles surgidos não podem ser transferidos de uma firma para a outra sem que haja custos. Esta constatação leva o autor a dois pilares que compõem a Visão Baseada em Recursos: (1) os recursos que, ao mesmo tempo, são raros e valiosos, possibilitam a criação de vantagem competitiva e (2), quando simultaneamente estes recursos são inimitáveis, insubstituíveis e 
intransferíveis, então pode vir a ocorrer a chamada vantagem competitiva sustentável, trazendo benefícios tanto no curto quanto no longo prazo. Trabalhar com a ideia de vantagem competitiva é relembrar também que as organizações alcançam melhores resultados quanto melhor estiverem adaptadas às oportunidades dos ambientes de negócios nas quais estão inseridas, retirando o maior valor possível de suas competências e recursos (ANDREWS, 1971; CHANDLER, 1962; PENROSE, 1959). Nesta monografia e, novamente de acordo com Barney (1991), o recurso a ser analisado foi o empregado levando em conta à categoria de capital intangível, caracterizado pela tecnologia empregada (Blockchain).

Resultado das perspectivas citadas e que estruturam o arcabouço sobre os recursos como uma visão estratégica, o modelo VRIO surge para investigar justamente a relação dos recursos com as vantagens competitivas, encontrando em Barney (1991) o seu prógono - assim aceito pela comunidade acadêmica. É importante salientar aqui a singularidade e importância da contribuição realizada por Barney (1991) no que tange ao aspecto da sustentabilidade da vantagem competitiva (PAVÃO; SEHNEM; HOFFMANN, 2011): anteriormente aos estudos deste, Porter (1983) já havia concretizado a noção sobre vantagens competitivas de firma, porém pelo prisma do ambiente externo, qualificando quais forças ambientais tinham maior interferência na concorrência entre diferentes players (SEHNEM, LAZZAROTTI; BANDEIRA-DE-MELLO, 2009). Ressalta-se então a relevância do conteúdo abordado por Barney (1991) quanto ao modelo VRIO: é sob sua interpretação que a presente monografia retratarse-à. Para fins de classificação, Barney (1991) elenca, da seguinte maneira, os componentes do modelo VRIO:

- (V)alor = recursos de valor que potencializam oportunidades do ambiente externo e combatem com mais eficiência as ameaças deste mesmo ambiente;

- $(\mathbf{R})$ aridade $=$ recursos pertencentes a um grupo restrito de players; 
- (I)mitabilidade $=$ condição da concorrência em copiar o recurso raro e valioso de uma determinada organização;

- (O)rganizável = o quão uma empresa está preparada e estruturada para obter ganhos dos recursos considerados raros, valiosos e difíceis de serem imitados. .

Figura 4 - Modelo VRIO

ADMINISTRAÇÃO ESTRATÉGICA E VANTAGEM COMPETITIVA

\begin{tabular}{|c|c|c|c|c|c|}
\hline \multicolumn{6}{|c|}{ O modelo VRIO } \\
\hline Valioso? & Raro? & $\begin{array}{l}\text { Oneroso de } \\
\text { Imitar? }\end{array}$ & $\begin{array}{l}\text { Explorado com } \\
\text { Organização? }\end{array}$ & $\begin{array}{l}\text { m Implicações } \\
\text { ? competitivas }\end{array}$ & $\begin{array}{l}\text { Implicações } \\
\text { econômicas }\end{array}$ \\
\hline Não & & & Não & Desvantagem & $\begin{array}{l}\text { Abaixo do } \\
\text { normal }\end{array}$ \\
\hline Sim & Não & & & Paridade & Normal \\
\hline Sim & Sim & Não & & $\begin{array}{l}\text { Vantagem } \\
\text { temporária }\end{array}$ & $\begin{array}{l}\text { Acima do } \\
\text { Normal }\end{array}$ \\
\hline Sim & Sim & Sim & Sim & $\begin{array}{l}\text { Vantagem } \\
\text { sustentável }\end{array}$ & $\begin{array}{l}\text { Acima do } \\
\text { Normal }\end{array}$ \\
\hline
\end{tabular}

() 2011 Pearson Prentice Hall. Todos os direitos reservados.

Fonte: Livro Administração: Teoria e prática no Contexto Brasileiro (2013)

Vale ressaltar que, de acordo com Barney e Hesterly (2007), se o recurso apresentado for valioso mas não raro, então cria-se o cenário de paridade competitiva: embora não sejam criadas vantagens competitivas a partir dele, a organização que não possuir este recurso corre o risco de se ver em desvantagem competitiva em relação aos concorrentes. Em não sendo recurso que gere tais vantagens competitivas, ele pode apresentarse como uma força das empresas no mercado. 


\section{Metodologia de Pesquisa}

A pesquisa foi efetuada com o apoio de um questionário qualitativo que buscou avaliar a utilização da tecnologia de Blockchain nos processos de supply chain. Este capítulo tratará sobre os moldes em que tal questionário foi realizado e quais são os perfis resumidos dos entrevistados, explicando o processo de coletagem de dados até 0 diagnóstico das respostas dadas.

\subsection{Tipo de Pesquisa}

Esta monografia, através de sua pesquisa, buscou elucidar a possibilidade do uso da tecnologia Blockchain como recurso gerador de vantagem competitiva sustentável para as organizações que atuam no setor de supply chain, levando em conta o atual nível de maturidade deste recurso nesta área e as oportunidades e obstáculos enfrentados no mercado. Deste modo, foi realizada uma pesquisa qualitativa, visando a compreensão de uma situação em específico (GODOY, 1995), qual seja: a do uso do Blockchain em cadeias de suprimentos e seu potencial de criação de vantagem competitiva sustentável.

Por conta da atual pandemia do coronavírus, não foi possível estabelecer contato direto com as empresas in loco, impossibilitando o estudo de campo, no sentido mais estrito desta palavra. As entrevistas foram ora conduzidas via aplicação Zoom, ora enviadas e respondidas por e-mail: nas vídeo-chamadas por Zoom, a duração destas oscilou entre 20 a $1 \mathrm{~h} 22$ minutos. Foram entrevistados sete gestores de empresas, entre prestadoras do serviço de Blockchain e usuários finais (seus nomes, cargos, formações, áreas, como responderam ao questionário e duração dos mesmos são descritos a seguir). Um entrevistado participou da pesquisa sob condição de anonimato de todos os seus dados, totalizando 
oito respondentes. Um roteiro - presente em anexo - com 10 perguntas estruturadas foi realizado, condicionado a uma questão primeira, de fundamental importância para esta monografia:

Há projetos envolvendo o Blockchain (ou expectativa de) na área de Supply Chain em sua empresa?

Quando as respostas foram afirmativas, conduziu-se as entrevistas com as 10 perguntas subsequentes; quando as respostas foram negativas, a pesquisa deu-se por encerrada. Nos oito casos afirmativos, sete participantes autorizaram a divulgação de seus nomes, de suas empresas e também a gravação das vídeo-chamadas, conduzidas via Zoom, e as entrevistas por e-mail. Ao todo, foram contactados 52 profissionais: cinco não demonstraram interesse na pesquisa (aproximadamente 10\%); oito participaram dela (15\%) e 39 não retornaram o contato (75\%).

A pesquisa dividiu-se em quatro grandes núcleos, quais sejam:

- Bloco I - Função do entrevistado;

- Bloco II - Blockchain na operação;

- Bloco III - Feedbacks e projeção de investimentos

- Bloco IV - Estratégia no setor de Supply Chain

Além dos blocos citados, foi aberto espaço para comentários complementares.

\subsection{Universo, Amostra e Seleção de Sujeitos}

A amostra englobou as empresas IBM, Vale, SAP, Procurement Garage e SCM Design: as três primeiras com atuação regional e global; a quarta com sedes em São Paulo e Miami e uma unidade no Rio de Janeiro e a quinta com sede em São Paulo. Vale destacar que, como empresas que atuam com tecnologia e com serviços de suporte a cadeias de suprimentos, seus escopos ultrapassam as regiões físicas onde encontram-se. Os contatos ocorreram via Linkedln e via canal de 
comunicação interna de funcionários da IBM, uma vez que o entrevistador trabalha atualmente nesta organização. A amostra realizada pode ser considerada como de conveniência.

Acerca dos critérios de seleção utilizados, foram estabelecidos os seguintes: (1) perfil - gestores e executivos da área de Tecnologia da Informação; (2) atuação - profissionais familiarizados com a tecnologia Blockchain, com gestão estratégica e envolvidos na prestação de serviços da tecnologia voltados para empresas com demandas nas áreas de supply chain. A tabela 1 mostra quais foram os entrevistados, bem como algumas características profissionais: 
Tabela 1 - Perfil dos profissionais entrevistados

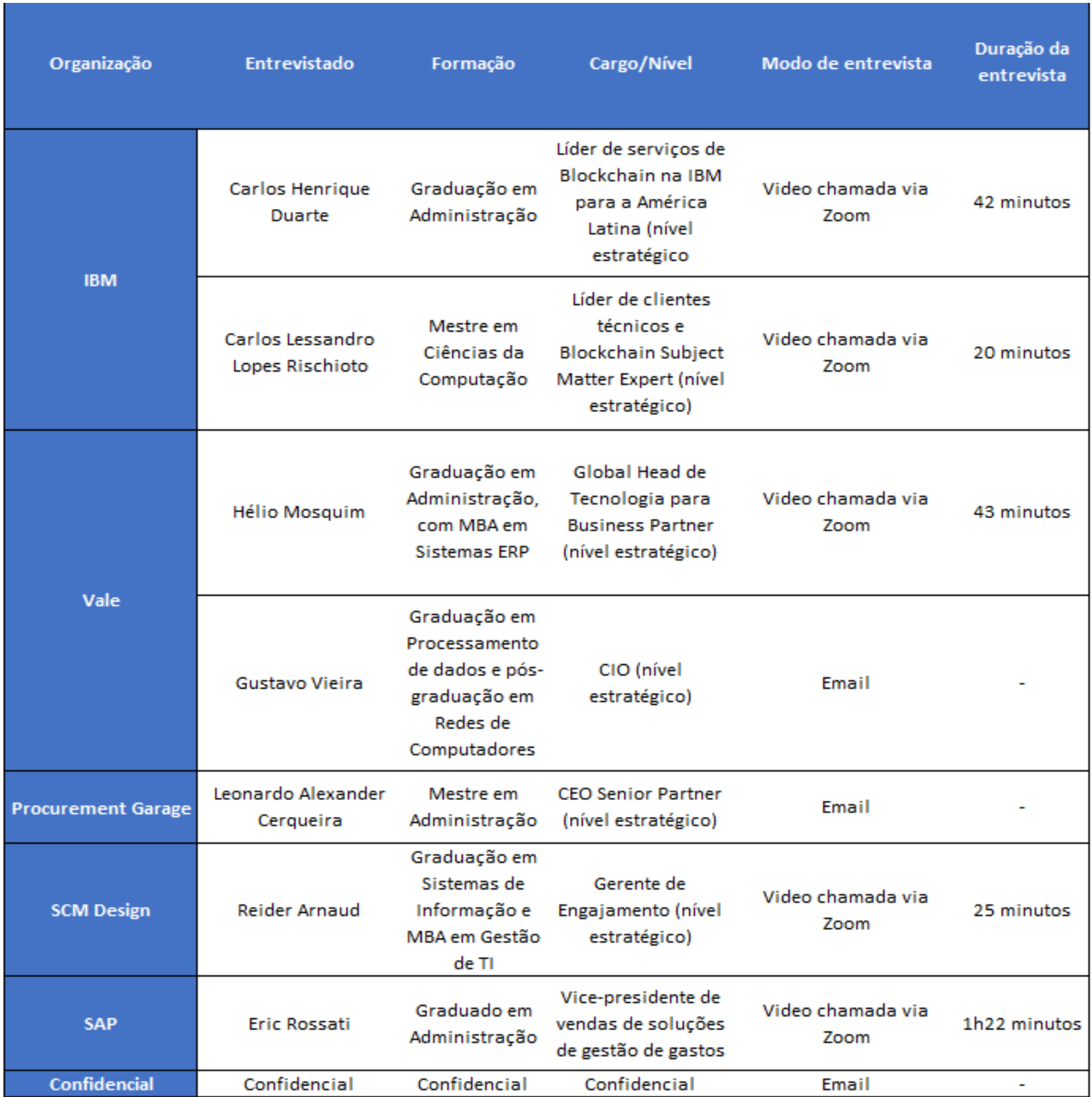

Fonte: elaboração própria. 


\subsection{O Procedimento de Coleta de Dados}

O questionário, contendo 11 perguntas, iniciou-se com uma questão-chave: em afirmativo para esta pergunta, prosseguiu-se com a pesquisa e as outras 10 perguntas; em negativo, a pesquisa foi encerrada. A questão-chave era a pergunta:

Há projetos envolvendo o Blockchain (ou expectativa de) na área de Supply Chain em sua empresa?

As empresas entrevistadas foram a IBM (setor de tecnologia da informação), A Vale (setor de mineração), a SAP (setor de softwares de gestão empresarial), a Procurement Garage (consultoria em Procurement e Supply Chain) e a SCM Design (setor de tecnologia da informação e serviços). O questionário procurou (1) enfatizar a função dos entrevistados; (2) o funcionamento do Blockchain na área de supply chain dos clientes parceiros; (3) como as soluções envolvendo a tecnologia foram desenvolvidas; (4) quais objetivos a serem alcançados ao ser utilizada a tecnologia nestes setores; (5) barreiras e oportunidades do mercado; (6) feedbacks de stakeholders; (7) expectativas de investimentos; (8) existência de diferenciação e geração de valor e (9) aumento nos níveis de eficiência/produtividade das atividades com Blockchain, além do cenário (10) em meio à e no pós-pandemia do coronavírus.

Como citado nas referências bibliográficas, a pesquisa procurou destacar questionamentos que pudessem fazer relação com a Visão Baseada em Recursos e o modelo VRIO preconizado por Barney (1991), de modo a estabelecer conexão com a área de Estratégia.

\subsection{Tratamento de Dados}

Feitas de forma virtual, todas as entrevistas - de perfil qualitativo foram disponibilizadas por vídeo-chamada ou email: as realizadas em vídeo-chamada tiveram seu conteúdo transcrito em sua totalidade. Optouse por realizar uma análise em blocos, dividindo o questionário em quatro partes: este modo permitiu a comparação das respostas, bem como a fácil 
interligação entre as mesmas, de modo a estabelecer constrastes e semelhanças quanto aos discursos analisados.

\subsection{Limitações do Estudo}

O questionário empregado pela presente monografia apresentou algumas barreiras de difícil solução: a primeira delas foi quanto a conseguir respostas de empresas de atuação direta na cadeia de suprimentos, os chamados clientes finais. O estudo realizado contou com empresas prestadoras do serviço de Blockchain, ou seja, empresas que vendem a solução para outros parceiros, estes sim da cadeia de abastecimento. Por este motivo, o prisma deste Trabalho de Conclusão de Curso está mais voltado para os profissionais da área de $\mathrm{TI}$ que empregam o recurso Blockchain em supply chain. Foi tentado o contato com diversas empresas do setor, mas infelizmente sem sucesso.

A segunda das barreiras está ligada à atual pandemia do COVID19. No meio da crise de saúde global, não houve a condição de poder visitar as empresas entrevistadas, o que prejudicou de sobremaneira a chamada pesquisa de campo. Neste sentido, as observações não-verbais que poderiam ser inferidas nos ambientes de trabalho foram perdidas.

Para além destas barreiras, existiram dificuldades quanto ao modo de realização das entrevistas: muitas das fontes primárias de informação contactadas não se dispuseram a responder ao questionário por videochamada e por e-mail. Há também a possibilidade de erros interpretativos quanto aos entrevistados que disponibilizaram suas respostas, bem como a simplicidade de algumas delas, especialmente as enviadas por e-mail. 


\section{Análise dos Resultados}

São apresentados, neste tópico, os levantamentos realizados com a pesquisa aplicada aos entrevistados, apontada no capítulo 3. Faz parte do presente capítulo a associação das respostas obtidas com o referencial teórico anteriormente elencado, cuja intenção é responder à questão deste Trabalho de Conclusão de Curso, bem como o embasamento com os objetivos intermediários.

$O$ roteiro segue a divisão entre os quatro blocos da pesquisa elaborada - (1) função do entrevistado; (2) Blockchain na operação; (3) feedbacks e projeção de investimentos e (4) estratégia no setor de supply chain -, também demonstrados no capítulo 3, a fim de melhor expôr a conexão das respostas com os tópicos apresentados no capítulo 2, quais sejam: a alusão com a tecnologia Blockchain e seu uso no mercado; os processos de inovação ligados a geração de valor, cooperação entre parceiros e competitividade; como a tecnologia pode ser utilizada em supply chain e, por fim, a relação do Blockchain com a ferramenta estratégica de Visão Baseada em Recursos, mais especificamente abordando como este recurso pode ser valioso, raro, imitável e organizável, caracterizando a análise do modelo VRIO. Por fim, ainda há a contribuição acerca de como o mercado reagiu e pensa em atuar no futuro dada a atual pandemia do COVID-19 (no momento em que este estudo foi realizado, a crise sanitária abarca, quase que por completo, o ano de 2020).

\section{1 Área, função e experiência dos entrevistados}

O primeiro bloco da pesquisa realizada com os oito entrevistados procurou entender qual a experiência dos mesmos no setor de supply chain. Além deste background, foram investigadas as formações acadêmicas de cada um, bem como suas atuais empresas e cargos. Vale ressaltar que um dos entrevistados pediu anonimato quanto à todas as 
informações acima citadas e, por isso, neste primeiro bloco, os perfis ficarão restringidos aos sete respondentes que autorizaram a divulgação de seus nomes e seus dados. Outro ponto importante a salientar-se é um já mencionado nesta monografia: como houve a dificuldade em obter respostas de contatos que atuam diretamente na área de supply chain, a pesquisa realizada contou com a colaboração de respondentes que atuam como prestadores de serviço do Blockchain para empresas parceiras que trabalham com cadeias de suprimentos, ou seja: empresas fornecedoras da tecnologia para clientes finais. Neste sentido, a maioria das entrevistas contam com profissionais da área de Tecnologia da Informação que atuam em projetos de supply chain de organizações que contrataram a solução.

O Bloco I - Função do Entrevistado - é composto pela seguinte questão:

1. Qual é seu cargo na sua empresa? Se atua/já atuou com Supply Chain, em quais áreas você possui/possuiu responsabilidade?

- Planejamento de Demanda;

- Movimentação de Materiais e Armazenagem (de insumos e produtos acabados);

- Compras;

- Importação e Exportação;

- Logística de Distribuição;

- Transporte;

- Outra? Qual?

O primeiro contato realizado foi com Hélio Mosquim Júnior, atual chefe global de tecnologia para parceiros de negócios da Vale, formado em administração pelo Centro Universitário Santo André e com $M B A$ em sistemas ERP pela PUC-PR. Mosquim trabalhou na área de inovação do time de tecnologia e transformação digital na Vale, em projetos multidisciplinares voltados para arquiteturas, soluções e parceiros de negócios, até assumir o atual cargo. 
Sobre a utilização do Blockchain e sua participação na área de supply chain, foi dada a seguinte afirmação:

"A Vale atua nas cinco regiões do mundo, em cerca de 30 países. A atuação da empresa com o Blockchain, além da área comercial, vai do inbound ao outbound, passando por toda a cadeia de suprimentos. Na parte de outbound, a maior parte dos clientes da empresa está no exterior, especialmente na Ásia. Na parte de inbound, a empresa trabalha em conjunto com a Petrobras, usando o Blockchain com a BR distribuidora, tendo maior controle e efetividade da cadeia de insumos." (Hélio Mosquim Júnior).

O segundo entrevistado foi Leonardo Alexander Cerqueira, graduado em comércio exterior, com extensão na Columbia University e CEO (Chief Executive Officer) na Procurement Garage, responsável pela gestão da empresa e por projetos de consultoria, tecnologia e educação focados em Procurement e Supply Chain/Logística. O entrevistado tem experiência em contratos com fornecedores nacionais e internacionais, desenvolvendo políticas e implementação de projetos nas áreas de materiais diretos (matéria-prima e embalagem) e indiretos (serviços, maquinaria e equipamento e TI), além de administração de projetos de risco nas áreas de supply chain e commodities.

A terceira colaboração foi dada por Carlos Lessandro Lopes Rischioto, com mais de 20 anos de carreira na área de Tecnologia da informação e mestre em Ciências da Computação pelo Instituto de Pesquisas Tecnológicas de São Paulo, atualmente líder técnico de Blockchain na IBM. Sobre sua experiência com o setor de supply chain, afirma a atuação como provedor da ferramenta:

"Nunca atuei diretamente na área de logística. Nosso papel é
aportar a tecnologia nos clientes, em projetos que envolvam estas
áreas, como por exemplo no processo de compras. Dentro da
própria IBM desenhamos um projeto de compras; na área de
importação/exportação com nossos clientes; na área de operações
logísticas e rastreamento. Atuei nestas áreas indiretamente e
através de projetos em clientes. Nossa missão é olhar para os
processos dos clientes e aportar a tecnologia." (Carlos Lessandro).

O quarto colaborador, Carlos Henrique Duarte, também é vindo da IBM, atuando como líder de serviços Blockchain para a América Latina. 
Possui mais de 23 anos de experiência no mercado de Tecnologia da Informação, sendo graduado em administração. Assim como o entrevistado anterior, este desenvolve serviços para serem implementados nas cadeias de suprimentos dos clientes, oferencendo suporte aos modelos de negócios das organizações parceiras.

A quinta entrevista foi concedida por Gustavo da Cunha Vieira, ClO da Vale, com quase 20 anos atuando na mineradora, graduado em processamento de dados pela Universidade Vale do Rio Doce e pósgraduado em redes de computadores pela Universidade Federal do Espírito Santo. Atuou em empresas de mineração, metais e papéis como gerente de aplicações de TI e gerente de projetos, além passar, nestas empresas, por setores como recursos humanos, administração de supply chain, planejamento de materiais e produção, administração de armazenagem e automação industrial; tem especialidade em planejamento estratégico de $\mathrm{TI}$, administração de vendas, sistemas $E R P$, arquitetura e administração de portfólios.

O sexto contato, por motivos de confidencialidade, pediu que seus dados acadêmicos e profissionais não fossem publicizados neste estudo.

A sétima contribuição foi dada por Reider Arnaud Bernucio, formado em Sistemas de Informação na Universidade Bandeirante de São Paulo, com MBA em Gestão de TI na Fundação Getúlio Vargas e co-fundador da startup de Blockchain para a área de saúde TokenHealth. Atualmente trabalha na empresa SCM Design como gerente de engajamento, conectando parceiros e clientes por meio de consultoria especializada em implementação dos sistemas SAP IBP, possuindo conhecimento abragente em supply chain. Ao longo dos seus 10 anos de carreira em tecnologia e gestão de projetos, atuou em empresas como Whirlpool (onde implementou o sistema SAP IBP e sistemas de CRM, além de realizar a migração do SAP R/3 para o SAP ECC), Ernest Young (também implementando o SAP IBP) e Accenture.

Oitavo e último entrevistado, Eric Rossati é formado em administração de empresas pela Universidade Paulista, atualmente trabalhando como vice-presidente de vendas de soluções de gestão de gastos na SAP, na unidade chamada ISM - companhia ARIBA, comprada 
pela SAP. Possui mais de 20 anos de carreira na área de TI, atuando como líder de vendas em companhias no Brasil e no México, tais como SAP, IBM e Oracle. Sua trajetória inclui a posição de diretor de vendas de soluções como S4 Hana, Cloud, CRM e soluções voltadas para e-commerce e supply chain, além da chefia de processos de inovação, alavancando transformações digitais nas áreas de compras e compliance de clientes e parceiros. A utilização da tecnologia Blockchain nas operações sob seu comando é estudada para um futuro próximo, especialmente dentro do sistema ARIBA, como evidenciado na fala abaixo:

"A nossa solução tem responsabilidade sobre todas as áreas citadas. Falamos muito com compras, ARIBA nasceu com esse intuito. Criamos eventos de compras (sourcing). Temos algumas tecnologias em compras, como sourcing, onde estão os provedores; temos a área de logística, garantindo que o contrato seja cumprido (compliance) e a automatização de compras com ERP. Nosso processo de ponta-aponta vai desde compras, passando pela negociação e jurídico, gestão de contratos e fazendo integração com supply chain no final, passando também por gestão de estoque.Temos planos futuros para o Blockhain atuar em todas estas pontas." (Eric Rossati).

\subsection{Uso do Blockchain na operação}

Para responder à pergunta que motiva o presente estudo, a tecnologia Blockchain foi considerada como um recurso sob o ponto de vista estratégico, capaz de gerar valor que pode ou não diferenciar e criar modelos de negócios dentro das organizações. A análise inicial sobre esta capacidade reside em como o Blockchain atua nas operações de supply chain ou nos serviços de prestadores que suportam as atividades dentro da cadeia para os clientes finais. Neste contexto, foi formulada a segunda questão da entrevista, pertencente ao Bloco II - Blockchain na operação:

2. Como a tecnologia funcionaria/ funciona nas operações de Supply Chain sob sua responsabilidade? 
Ao ser indagado sobre o uso da ferramenta nas operações da Vale, Hélio Mosquim, entrevistado 1, pontuou que é preciso entender primeiro se o problema a ser solucionado demanda esforços com a plataforma digital. Para ele, uma vez identificada a possibilidade do uso, então os procedimentos a serem sustentados pelo Blockchain passarão a ganhar maior confiabilidade entre os agentes envolvidos, tal como exposto por ØInes, Ubacht e Janssen (2017):

"Em alguns casos envolvendo vários players, cujo elemento de confiança precisa predominar na rede compartilhada, o Blockchain é aconselhável. Na parte de supply chain, a tecnologia foi usada inicialmente no comercial/vendas, com o relacionamento de clientes na Ásia: elementos como colocação do pedido, ordem de vendas, estabelecimento do contrato, entrega dos produtos e, posteriormente, o pagamento, contaram com a utilização da tecnologia. O processo envolveu clientes e bancos, fornecendo maior transparência, agilidade e confiança." (Hélio Mosquim)

Ponto importante a ser destacado na fala do entrevistado é o surgimento das discussões acerca de quem seria o detentor da propriedade intelectual da solução, evidenciando um problema que, a princípio, pode não ter uma solução tão trivial:

"A Vale percebeu, juntamente com outros parceiros que usam a tecnologia, o início da discussão sobre propriedade intelectual. Quem é o dono de uma solução em rede? O capital intelectual é de quem? Se a empresa não tem o interesse em vender a solução, ela então compartilha a mesma. Dependendo do parceiro, pode haver um problema com a implementação da tecnologia: a Vale perdeu um ano com um parceiro em discussões sobre propriedade intelectual." (Hélio Mosquim)

A fala de Carlos Lessandro, terceiro entrevistado, corrobora o referencial teórico utilizado pelo trio de autores acima, a respeito da confiabilidade que o Blockchain pode trazer para os serviços da cadeia de suprimentos: ao enfatizar as soluções fornecidas pela IBM aos seus 
parceiros, Lessandro inclui, além da confiabilidade, ganhos nos índices de rastreio, velocidade e eliminação de conflitos:

"Temos muitos projetos de rastreamento de cadeia nacional e com a parte de importação/exportação e processos alfandegários: projetos para otimizar a documentação alfandegária, a parte de liberação aduaneira e rastreamento de cargas, contêiners (projeto TradeLens) e rastreamento de cadeia fria, além de rastreamento de produtos, como alimentos. O Blockchain ajuda muito na otimização de processos e simplificação de trâmites de documentação e informação entre diferentes participantes da cadeia de suprimentos. A tecnologia elimina disputas (desencontro de informações), aumenta a velocidade e a confiança."(Carlos Lessandro)

Quarto entrevistado, Carlos Duarte discorre que, nos serviços com os quais trabalha para a cadeia de suprimentos, as regras a respeito de como as operações funcionarão com o Blockchain trazem maior estabilidade, segurança e consentimento das informações trocadas (CROSBY et al., 2016), pontos que surgem quando há o emprego da tecnologia funcionando justamente dentro de uma rede descentralizada e pública (WALPORT, MGCSA et al, 2016):

\footnotetext{
"Processo bastante interessante é o da conciliação de informações. Quando eu tenho uma base segura do ponto de vista da inserção de dados - todos os participantes da cadeia estão de acordo com o que está sendo resgistrado -, as regras são iguais para todos, existe um consenso da maneira como está sendo registrado as informações, eu não preciso conciliar. Se ocorre um problema, identifico rapidamente e as disputas são resolvidas na hora, exatamente por conta da visibilidade e do registro, que é público." (Carlos Duarte)
}

Nos planos futuros da SAP, especialmente no módulo de compra ARIBA, Eric Rossati, oitavo entrevistado, aponta como o Blockchain corroboraria para a rápida e eficiente correção de erros advindos de provedores - ganhos alcançados pela característica de rastreablidade da ferramenta - , além de citar a conexão da tecnologia com outras dentro da indústria 4.0: 
"No futuro, dentro da solução ARIBA, dentro dos nossos módulos, teremos o Blockchain. No futuro, isso estará linkado com inteligência artificial. Você poderia trabalhar num processo de recall de carros, retirando o trabalho manual e indo até o provedor que forneceu as peças, tendo um maior controle de qualidade. O Blockchain ajudaria muito nesse quesito de rastreabilidade. Você veria qual foi a peça defeituosa, pertencente a determinado lote, e chegaria no provedor, ao invés de fazer o processo contrário, muito mais trabalhoso." (Eric Rossati)

Ao tratar dos processos de inovação que contam com cooperação e parcerias entre os agentes pertencentes ao mesmo elo de Blockchain, a entrevista buscou, uma vez mais, conectar a prática das organizações com o referencial teórico do estudo, especialmente teorizados por Gobble (2014), Govindarajan (2016), Ramaswamy e Ozcan (2014), OECD (1992) e Solleiro (2005): ponto quase pacífico entre todos os entrevistados, a característica de cooperação aparece de modo a sustentar a viabilidade de muitas das operações, bem como os ganhos por partes dos participantes, destacando inclusive a participação de startups. Este cenário foi posto aos participantes da pesquisa por meio da pergunta 3 :

\section{O Blockchain serálfoi desenvolvido apenas pela empresa? Houve/haverá alguma parceria externa com outras empresas (projetos de código aberto ou criação de ecossistemas)?}

A respeito da cooperação que ocorre entre a Vale e seus parceiros, Hélio Mosquim assinala e sugere:

"O trabalho envolve o time de arquitetura com parceiros globais. $\mathrm{Na}$ Ásia, tentamos com um parceiro global, mas ficamos muito tempo discutindo propriedade intelectual e, no fim, conseguimos a solução com uma startup: elas são mais ágeis e seguras. Sei que a PUC-Rio tem um laboratório muito forte de Blockchain e seria uma boa oportunidade para conversar com a universidade." (Hélio Mosquim) 
O entrevistado ainda aponta como podem surgir alguns modelos novos de negócios dada a cooperação:

"Há várias opções, como redes com tecnologia open source; há parceiros que não se preocupam com o capital intelectual e sim com o fornecimento do serviço; a solução pode virar um produto, sendo compartilhado com outras empresas que tenham o mesmo problema (dividindo custos ou monetizando o serviço). Há vários modelos de negócios a serem explorados ao criar soluções em rede. (Hélio Mosquim)"

O mesmo diagnóstico pode ser retirado nas contribuições de Carlos Lessandro, que deu ênfase, em sua fala, aos serviços de Blockchain baseados na Nuvem, que podem ser moldados em conjunto com os clientes, fruto da iniciativa Hyperledger, criação da IBM, e também aos serviços de código aberto e as iniciativas que a organização tem com programas voltados para startups. Carlos Duarte, outro entrevistado ibmista, reforça a fala do colega de empresa e complementa citando que, atualmente, há mais de 200 empresas trabalhando em conjunto com a IBM na solução Hyperledger. Gustavo Vieira, da Vale, sinaliza que a IBM também é uma parceira de negócios para a mineradora e Eric Rossati embora sem poder citar nomes de parceiros -, afirma que a SAP trabalha com co-desenvolvimento, oferecendo soluções customizadas para seus clientes globais por meio de código aberto. As respostas obtidas com a entrevista número 6 citam as redes IBM Food Trust - rastreabilidade na cadeia de alimentos desde o produtor do campo, passando pelas côndolas dos supermercados, até chegar no cliente final - e a TradeLens, parceria novamente da IBM, desta vez com a Maersk, cujo intuito é o de rastrear conteinêrs em transporte marítimo de importação e exportação, bem como toda a documentação por trás dessas movimentações. Todos estes depoimentos sinalizam que o padrão do mercado é, pelo menos por hora, construído com base na inovação do Blockchain auferida pela comunhão de esforços entre os players das cadeias de suprimentos.

Entre os ganhos adquiridos com a implementação do Blockchain nas cadeias de abastecimento há a solução de entraves 
relacionados, principalmente, com 0 rastreio de bens e cláusulas contratuais, como pontuado por Sivula, Sgamzuzzoha e Helo (2018). A pergunta 4 do questionário versa sobre este ponto:

\section{Quais os principais ganhos que o Blockchain trará/trouxe para} as operações de cadeia de Suprimentos?

Os dados obtidos nas entrevistas vão ao encontro da teoria, como levantado por Eric, da SAP, em sua fala, que também evidencia a interface com diversos sistemas de gestão logísticos:

\footnotetext{
"Pensando no Blockchain, qualquer produto e centavo deve ser extremamemente rastreável. De tudo o que o Blockchain pode fazer, pra mim o mais importante é a rastreabilidade. Compliance ganha muito com isso também. Podemos mitigar riscos dos provedores se houver algum desastre natural que afete o fornecimento ou o leadtime, como ocorreu com a Kingstone num tsunami em 2017. Minha visão é que terá muita integração com sistemas ERP. O conceito Blockchain vai integrar as soluções. O mundo ideal deveria ser de todas as empresas terem o sistema core e os sistemas satélites - de compras, $\mathrm{RH}$ - interligados." (Eric Rossati)
}

Na Vale, Hélio Mosquim destaca a importância da transparência, especialmente em processos com alto volume e grandes chances de reconciliação: para ele, o Blockchain traz consigo níveis sem precedentes de segurança, transparência e agilidade, elementos fundamentais para a cadeia de suprimentos. Em sua opinião, não há mais perdas com reconciliação, pois todos os dados estão disponíveis em tempo real, desde a colocação do pedido até o pagamento, no caso de suprimentos, ou da colocação do pedido até o recebimento, por parte do cliente. Sua fala enfatiza também o ponto trazido por Eric ao citar a junção do Blockchain com os sistemas ERP:

"O ERP é o sistema central de gestão empresarial que tem todas as transações de negócios, então essa camada de Blockchain se integra com a transação do negócio e possibilita um resultado final melhor. A 
tecnologia precisa permear todo o sistema de gestão, de ponta-aponta, e o Blockchain vem pra complementar o sistema de gestão transacional dentro das cadeias de supply chain." (Hélio Mosquim)

Carlos Lessandro, por sua vez, também indica ganhos quanto a eficiência, velocidade, segurança e até ganhos de posicionamento de marca - ao tratar da origem lícita de produtos - , além de frisar as centenas de patentes obtidas pela IBM no que tange ao uso do Blockchain nos processos de suprimentos, como no rastreamento de alimentos. Carlos Duarte tabém cita a rastreabilidade como um ganho, bem como a diminuição de custos operacionais, além de maior previsibilidade e monitoramento. Para ele, os ganhos ocorrem porque o Blockchain dá visibilidade aos que antes eram "pontos cegos" dentro da cadeia de supply chain (WILLIAMS, 2015). Reider Arnaud, sétimo entrevistado, reforça a possibilidade de maior transparência dos ativos nas operações e destaca como a tecnologia veio, especialmente, para eliminar intermediários, situação descrita por Nakamoto (2008) ao falar sobre as transações eletrônicas perfomadas pelo aparato digital.

Ao falar das principais dificuldades e oportunidades quando da implementação do Blockchain, a entrevista fecha o Bloco II com a quinta seguinte indagação:

\section{Quais são as barreiras mais difíceis de serem superadas quanto à implementação da tecnologia? E as maiores oportunidades?}

Hélio Mosquim, da Vale, salienta a relação com os clientes como um ponto que pode trazer discordâncias e gerar entraves e que deve ser visto com maior cuidado pelos que utilizam o Blockchain em suas soluções de supply chain:

"Além dos aspectos técnicos, como integração com ERP e todo o processo de ponta-a-ponta, outro grande desafio é a adoção: não adianta a Vale ter todos os códigos funcionando perfeitamente se os clientes, bancos e outros atores não utilizarem a rede. Um trabalho de 
engajamento entre todas as áreas, de ponta-a-ponta, garante o maior sucesso, seja no inbound ou no outbound." (Hélio Mosquim)

A cultura das organizações e o nível de resistência a mudanças foram algumas das observações mais citadas por todos os entrevistados: Leonardo Alexander, ao elencar esta dificuldade, lembra também do nível de maturidade que as empresas precisam ter para aceitar este novo processo; Carlos Lessandro menciona a barreira do modelo de governança e a resistência quanto à adoção de um modelo único dentro da rede, que seja eficiente e aceito por todos; Carlos Duarte sinaliza o quão difícil é uma empresa perceber que precisa mudar de estratégia, abrindo mão de um determinado nível de controle pra que ela possa ter controle numa rede de Blockchain, uma vez que este controle será compartilhado, que os agentes estão dentro de um ecossistema e que é importante para a diferenciação, diante da concorrência, que a organização abdique de um controle mais robusto para auferir benefícios diante da concorrência; o entrevistado número 6 sintetiza as dificuldades como sendo partes da barreira cultural em relação ao compartilhamento de informações entre si; Reider Arnaud faz coro às afirmações, afirmando que a "evangelização" da ferramenta é difícil de ocorrer, especialmente quando alguns executivos nível-C desconhecem seu potencial e, portanto, não conseguem elaborar projetos; por fim, Eric Rossati comenta sobre o preconceito contra a ferramenta e contra a digitalização e ressalta o que é, pra ele, a maior dificuldade:

\footnotetext{
"Novas habilidades e novos aprendizados são dificuldades. Sobre supply chain e Blockchain: antes não existia a necessidade da rastreablidade como vamos precisar e, mesmo que tivesse, faríamos de outros modos. Agora eu preciso de um cara que entenda isso num nível de rastreablidade maior, isso é uma nova habilidade. Preciso é ter inteligência numa compra estratégica, para eu garantir a compra em tempo e na qualidade que eu desejo" (Eric Rossati)
}

A respeito das oportunidades, chama a atenção o emprego de métodos ágeis feito pela Vale: 
"O ponto positivo é a abordagem de agilidade: em modelos com grande incerteza, a melhor abordagem é a abordagem por design, conseguir entender o problema por meio de design thinking. A partir do momento que você faz um MVP, você combate o investimento e consegue provar o valor. Essa foi a maneira que a Vale conseguiu com maior sucesso avançar em Blockchain. No modelo tradicional, com toda especificação do projeto, o custo era altíssimo e a chance de dar certo era baixa, porque a tecnlogia era nova e ajustes eram necessários." (Hélio Mosquim)

Carlos Duarte expõe que indústrias extremamente intermediadas podem ganhar com a eficiência trazida pelo Blockchain, principalmente as que tiverem muitas disputas e reconciliações a serem feitas; Eric Rossati vê oportunidades de geração de emprego nas empresas de manufatura que optarem pela implantação de processos digitais, além do gerenciamento de processos supply chain.

\subsection{Feedbaks e projeção de investimentos}

Para entender o nível de adoção e aceitação da plataforma Blockchain ao longo dos clientes que já utilizaram ou tem projeções para utilização da mesma no futuro, foi incluída na entrevista a pergunta que se segue e que abre o Bloco III do questionário - Feedbacks e projeção de investimentos:

6. Há feedback trazido pelos stakeholders quanto aos resultados obtidos pós-efetivação da tecnologia em seus processos?

Alguns dos retornos positivos foram percebidos de modo quantitativo, como no caso das operações suportadas pela Vale: de acordo com Hélio Mosquim, o maior indicador de satisfação dos parceiros da mineradora foi o aumento de dois para sete clientes, com previsão para alcançar 20 no curto prazo, o que configura, para ele, o interesse e os benefícios da ferramenta no mercado. Carlos Duarte, da IBM, afirmou que os resultados dos serviços prestados foram extremamente positivos e 
recebidos rapidamente, muito por conta da fácil integração da tecnologia com os API's fornecidos na Cloud da empresa. Em relação aos outros entrevistados, por motivos de confidencialidade com os clientes finais, não foi possível levantar maiores detalhes sobre estes feedbacks, a não ser que os retornos foram positivos, como assinalado na entrevista número $6 \mathrm{e}$ também por Carlos Lessandro, pontuando que nem sempre os clientes estão dispostos a compartilhar que ganhos obtiveram com o uso do Blockchain.

Este bloco tratou, ao mesmo tempo, da perspectiva em termos de investimentos que os entrevistados poderiam compartilhar e projetar para o uso do Blockchain em supply chain (a pergunta foi formulada em ordem de grandeza e de proporção, não mencionando valores nominais). Neste contexto foi feita a sétima pergunta:

\section{Na sua visão, qual poderia ser o valor investido na área nos} próximos anos?

As respostas obtidas variaram de acordo com o tipo de serviço implementado, a necessidade e condição de sustentabilidade no longo prazo da implementação, o volume de busca por inovação e a capacidade de autofinanciamento das redes de Blockchain. Na Vale, por exemplo, Hélio Mosquim não fez uma projeção em termos de proporção, mas afirmou que o primeiro ponto a ser estudado neste quesito é a relevância do negócio, partindo da premissa de que o projeto precisa ser sustentável e "se pagar". Na mineradora, os investimentos são formulados por meio de uma prospecção do Produto Mínimo Viável (ou Minimum Viable Product MVP): o investimento inicial é considerado baixo e, conforme o sucesso da aplicação, o esquema de self-funding é empregado, tornando a solução sustentável e escalável. Para o segundo entrevistado, Leonardo Alexander, a projeção é de duplicar os investimentos da Procurement Garage. Carlos Lessandro, IBM, acredita que os investimentos aumentarão de três a quatro vezes nos próximos dois ou três anos em relação ao nível de 2020. Gustavo Vieira, da Vale, traça um cenário com investimentos entre $0,5 \%$ e $1,5 \%$ do faturamento da empresa nos próximos exercícios fiscais. Já para Reider 
Arnaud, a questão é vista por um prisma mais personalizado, com o cálculo sendo realizado por hora/cliente: algumas empresas preferem fazer 0 investimento por hora, de modo a acompanhar se os esforços financeiros para a implementação do Blockchain de fato valem a pena. Por sua vez, Eric Rossati prevê uma triplicação dos investimentos na área, muito por conta do novo perfil que a pandemia trouxe para os negócios, com as atenções cada vez mais voltadas para a qualidade dos fornecedores e para soluções digitais que potencializem a compra de insumos. Ele complementa indicando que o mercado vai se atentar cada vez mais justamente para as fontes das matérias-primas e vê as empresas replanejando ações que tomariam em cinco anos para serem tomadas no próximo biênio, sob pena de falirem, sumirem do mercado.

Tais projeções, embora cercadas de incertezas em meio ao atual quadro de pandemia e a queda das economias globais, traçam, em sua maioria, um cenário condizente com o panorama trazido pelo estudo da Delloitte (PAWCZUK et al., 2020) no capítulo 2 deste Trabalho de Conclusão de Curso, qual seja: de crescente investimento na execução de projetos de Blockchain.

\subsection{Estratégia no setor de Supply Chain}

O quarto e último bloco, presente na pesquisa realizada com os oito entrevistados citados no capítulo 3, finaliza o roteiro deste capítulo 4 .

A fim de possibilitar a resposta para a indagação central do presente estudo, três perguntas foram formuladas neste Bloco IV - Estratégia no setor de Supply Chain:

8. Como você avaliaria a possibilidade de o emprego do blockchain permitir uma diferenciação da sua empresa diante da concorrência (qual seria a geração de valor)? Seria difícil copiar a tecnologia ou sua aplicação?

9. Como a utilização do Blockchain aumentou/aumentaria o nível de eficiência/produtividade dos processos em sua área? 


\section{Como a pandemia afetou a estratégia de utilização do Blockchain na área de Supply Chain?}

A teoria escolhida para diagnosticar se, de fato, o Blockchain gera vantagem competitiva, é conhecida como a desenvolvida por Barney (1991) e chamada de modelo VRIO, pertencente a ferramenta da área de estratégia denominada Visão Baseada em Recursos. É este o contexto no qual as três perguntas acima citadas foram elaboradas: na pergunta 8, avaliou-se o quão valioso, raro e imitável seria o recurso; as questões 9 e 10 conduzem o estudo a entender se o recurso é também valoroso e organizável, a ponto de gerar sustentação de si próprio no longo prazo.

$\mathrm{Na}$ Vale, Hélio Mosquim cogita a possibilidade de o recurso poder gerar vantagem competitiva se atrelado a outras tecnologias, mas alerta também para o cenário descrito por Barney e Hesterly (2007) como sendo o de paridade competitiva. Sua análise, sobre a pergunta 8, é taxativa: o Blockchain não é um recurso gerador de diferenciação quando atua de forma isolada:

"Em alguns aspectos, vai fazer sentido formar alianças com a concorrência para a ajudar a indústria como um todo - não será uma vantagem competitiva, mas será um processo que beneficiará a todos. Em outros pontos, há maior competitividade, como a parte comercial: outras mineradoras utilizam o Blockchain. O que diferencia em si não é a tecnologia, não importa de onde você utliza ela. O que vai diferenciar, de fato, é o modelo para a solução com os seus players e o modelo de negócio como vantagem competitiva. Quando você combina o Blockchain com uma série de outras tecnologias, o modelo pode vir a ser disruptivo. Quanto mais as empresas pensarem em modelos sustentáveis, mais vão se diferenciar no mercado. $O$ diferencial não é o Blockchain, mas o modelo em si." (Hélio Mosquim)

Carlos Lessandro, da IBM, traz outra perspectiva: para o líder técnico, o Blockchain pode atuar como um recurso valioso. É importante frisar, todavia, que Carlos cita esta afirmação como sendo o provedor do 
serviço e não alguém que trabalha numa indústria direta de supply chain. Segue abaixo sua análise:

"Estamos levando a tecnologia para os clientes para eles se diferenciarem. O Blockchain pode diferenciar muito os clientes nas mais diversas áreas. O nosso diferencial competitivo está em criar a tecnologia, justamente o fato de sermos os criadores e mantenedores do HyperLedger, isso é um diferencial competitivo nosso em relação a outros fornecedores de tecnologia. Estamos do outro lado do balcão, estamos distribuindo e implementando a tecnologia para os clientes." (Carlos Lessandro)

Carlos Duarte deixa claro, em sua declaração, que a IBM pretende liderar o segmento e fazer de seu background uma vantagem competitiva sim diante de outros players. Contudo, a premissa é a mesma do entrevistado anterior: a diferenciação estaria no processo da IBM, que é uma prestadora de serviço de $\mathrm{TI}$, e não nos concorrentes atuantes nas áreas de suprimentos:

"A IBM tem investido pesadamente em Blockchain há mais de cinco anos, temos muitas patentes. O nosso investimento tem sido bastante pesado, o que justifica a liderança da IBM no mercado de Blockchain. Ele está localizado no ponto de vista de produto: nós temos o IBM Blockchain Plataform, uma suit de administração que é multi cloud; não é necessário estar na máquina/rede da IBM para usar o serviço, o que gera maior flexibilidade para nossos clientes. Do ponto de serviços e de criação das redes, a IBM não só foi contratada pra desenvolver como em alguns casos ela tornou-se sócia." (Carlos Duarte)

Para o entrevistado número 6 , o Blockchain possibilita sim a diferenciação no modelo de negócios, evidenciando um aspecto valioso do recurso, como apontado pelo mesmo sobre o caso da TradeLens, possibilitando a união de uma empresa de transportes marítimos com uma empresa do setor de tecnologia. Já o entrevistado número 7, Reider Arnaud, aposta na propagação e conhecimento da tecnologia como fonte de vantagem e diferenciação: 
"A diferenciação está em mostrar o valor para os clientes, evangelizálos sobre a rede e o quão grande é o Blockchain. Você pode formar uma rede ou uma consultoria, outras empresas irão atrás de você, pra entender sua operação e a tecnologia. É preciso estudar e ter um conhecimento profundo na tecnologia e no desenvolvimento, é preciso modelar muito pra chegar a um negócio. O código é da Ethereum, é público, mas é preciso investir muito tempo e conhecimento." (Reider Arnaud)

Eric Rossati, da SAP, crê que as vantagens intrínsecas do Blockchain vão modelar geração de valor e faz um alerta e um diagnóstico interessante sobre a solidificação do uso da tecnologia e sua interface com sistemas ERP:

"A SAP se posicionará antes, porque ela tem a maior base de ERP implementada no mundo, mas a Oracle virá atrás, todas as empresas de ERP virão atrás, assim como as empresas satélites e as empresas com mais dinheiro, que poderão ter uma particpação maior no mercado, fazendo com que outras empresas sumam. As empresas, pra serem sustentáveis no longo prazo, precisarão obrigatoriamente dessa tecnologia, será o mínimo para poder competir. Você não tem Blockchain? Acabou, não vai existir... se você tiver um software de gestão sem estar habilitado pra transacionar com o Blockchain, já era: virá alguém que colocará uma solução e tomará o lugar. Com o tempo isso ocorrerá. O Blockchain permite que a gente rastreie onde ocorre algo errado na cadeia. Eu não gastaria um investimento num ERP sem Blockchain." (Eric Rossati)

Sobre a questão 9, que traz a avaliação sobre o Blockchain ser valioso e organizável, Hélio Mosquim aponta:

"Todo processo com altíssimo volume, com centenas de milhares de milhões de transações, mesmo usando sistemas ERP, qualquer divergência precisa ser resolvida por processos manuais, você é muito mais reativo do que proativo. O Blockchain te traz o dado único em tempo real, eliminando o retrabalho de conciliação, com um nível de eficiência sem precedentes. Tanto no inbound quanto no outbound 
já vivenciamos as experiências de processos mais eficazes." (Hélio Mosquim)

Leonardo Alexander, por sua vez, diz que a eficiência nos processos que comanda fica a cargo da segurança e dos processos de validações das operações. Carlos Lessandro segue a linha do primeiro entrevistado ao fazer suas considerações sobre o projeto TradeLens:

"Houve simplificação do processo. Antes haviam mais de 200 documentos gerados e transmitidos manualmente entre os participantes da cadeia. Hoje, com o TradeLens, você consegue fazer isso de forma automática, o trâmite é muito mais rápido, reduz bastante o tempo e o esforço para fazer a troca de informação e a liberação de documentação entre os participantes. Vemos melhora na velocidade e redução de retrabalho - documentação com problemas e a necessidade de reenviar, ressolicitar..." (Carlos Lessandro)

Carlos Duarte ilustra os ganhos em eficiência do Blockchain citando um outro projeto da IBM - FoodTrust - elencando também a possibilidade de uma rastreabiliadade mais robusta:

"Usamos com o Walmart a solução chamada FoodTrust, um caso de rastreabilidade de cadeia de suprimentos para fins de recall alimentar. Você tinha uma ineficiência em descobrir a fonte dessa comida num momento de crise... tem a história do pacote de manga, que a Walmart fez um teste pra rastrear o produto: demorou sete dias para o gerente obter a resposta e ela ainda veio errada. Hoje, a mesma informação está na mão da pessoa em dois segundos com o Food Trust. "(Carlos Duarte)

Tanto para o entrevistado número 6 quanto para Reider Arnaud, o ganho em eficiência - dando o status de valoroso para o Blockchain - está na maneira como o aparato digital aumenta a visibilidade e a rastreabilidade das atividades da cadeia. Eric Rossati dá, em sua fala, o reforço quanto ao poder de rastreabilidade do Blockchain, complementando sua análise ao afirmar que o setor de compliance também obtém ganhos expressivos de produtividade. 
A pesquisa chega, enfim, a sua décima e última pergunta, que também objetiva entender se o Blockchain é valoroso e organizável, mas agora levando-se em consideração quais impactos foram sentidos positivos ou negativos - diante da pandemia do coronavírus em termos de investimentos. Desse modo, o estudo oferece um panorama atualizado de como a tecnologia está sendo vista pelo mercado em tempos de crise e possibilita a análise da viabilidade de seu emprego no longo prazo, o que caracteriza um recurso que gera vantagem competitiva sustentável.

Contrariando um dos aspectos que pode levar o Blockchain a ser um recurso que se encaixe nas condições do modelo VRIO, Leonardo Alexander afirma que a pandemia retardou a tomada de decisões pelos clientes, sobretudo acerca da adoção da solução. Hélio Mosquim enxerga que processos tecnológicos passarão por uma rápida e intensa transformação, exigindo que as empresas se adaptem e acelerem seus aprendizados. Carlos Lessandro aponta fases distintas: num primeiro momento, a pandemia fez os clientes redirecionarem seus investimentos; contudo, ele enxerga uma retomada mais rápida do Blockchain nesta virada de ano e início de 2021. Carlos Duarte enfatiza o mesmo que foi dito por Hélio Mosquim e Carlos Lessandro, reiterando que existe uma oportunidade do Blockchain se popularizar ainda mais, mas que o crescimento da plataforma está atrelado a quão dispostas as empresas estarão, nos próximos meses, a investirem em inovação digital. Com um tom mais pessimista, Reider Arnaud crê que as empresas fecharam-se para novos processos de inovação, travando projetos e investimentos: o foco voltou-se para a operação tradicional e não mais pela busca de valor gerada pela adoção do Blockchain. Finalizando a pesquisa, Eric Rossati pontua que o uso do Blockchain aumentou consideravelmente, resultado de parte dos esforços em melhorias de processos digitais como um todo: "A pandemia acelerou esta adoção, que caiu pela metade em termos de tempo de implementação", afirma. Eric reassegura que empresas sem o Blockchain na área de supply chain irão falir em poucos anos e cita o exemplo das assinaturas digitais como um campo de grande crescimento em meio à pandemia. 


\section{Conclusão}

Este estudo buscou analisar, por meio da ferramenta estratégica VRIO, a capacidade do recurso Blockchain gerar vantagem competitiva sustentável para empresas que atuam em operações dentro da cadeia de suprimentos. O advento do Blockchain trouxe consigo uma grande expectativa quanto sua utilização no mercado de criptomoedas, mas seus ganhos se estendem para muito além das moedas digitais: o passar do tempo e as experiências de mercado demonstraram que, este importante componente da chamada Indústria 4.0, também tem sua aplicabilidade nos serviços de supply chain. Com gargalos, ineficiências e um vasto potencial a ser explorado, o Brasil desponta como um dos países onde a tecnologia pode gerar diversos benefícios, entre eles a maior competitividade das empresas que compõem o mercado nacional de suprimentos e abastecimento.

Embora promissor, barreiras ainda impedem que o Blockchain alcance seu potencial disruptivo em muitas das cadeias de serviços e produtos no país. Se, por um lado, a iniciativa privada tem buscado novidades e melhores performances sobre a tecnologia, por outro, a falta de interesse dos gestores públicos e de políticas de fomento à massificação e ensino da ferramenta configuram-se como um entrave para maiores ganhos de escalas e produtividade com este novo recurso tecnológico. Em meio à uma pandemia que assolou e continua a espalhar seus efeitos sobre o mundo quase que por um ano inteiro, dificuldades emergem em grande volume, muito embora possibilitem também o surgimento de novos negócios com o Blockchain.

O entendimento do atual contexto da empregabilidade do Blockchain nas cadeias de supply chain, bem como seu potencial disruptivo e gerador de vantagem competitiva sustentável, pode ser melhor compreendido neste estudo por meio de uma pesquisa qualitativa envolvendo oito entrevistados de cinco diferentes empresas, prestadoras de serviços ou clientes finais 
dentro das cadeias de suprimentos, em operações nacionais e internacionais. Esta compreensão abordou quatro pilares teóricos apresentados neste estudo - Blockchain, processos de inovação, logística e supply chain e Visão Baseada em Recursos -, culminando na análise a respeito do quão primordial, essencial e único pode ser o Blockchain dentro de um modelo de estratégia conhecido como VRIO, fazendo com o que a tecnologia surja com uma vantagem competitiva sustentável para seus adotantes.

Organizados todos os dados e discursos obtidos por meio da entrevista aplicada, chega-se à conclusão de que o Blockchain, dado o momento atual, ainda não pode ser considerado plenamente como um recurso que apresente vantagem competitiva sustentável para a maioria das empresas participantes do estudo. Elencados os pontos de valor, raridade, imitabilidade e organização e considerando as nuances de classificação dentro do modelo VRIO e as entrevistas, o seguinte cenário é caracterizado neste Trabalho de Conclusão de Curso: 
Tabela 2 - Modelo VRIO e perguntas do questionário

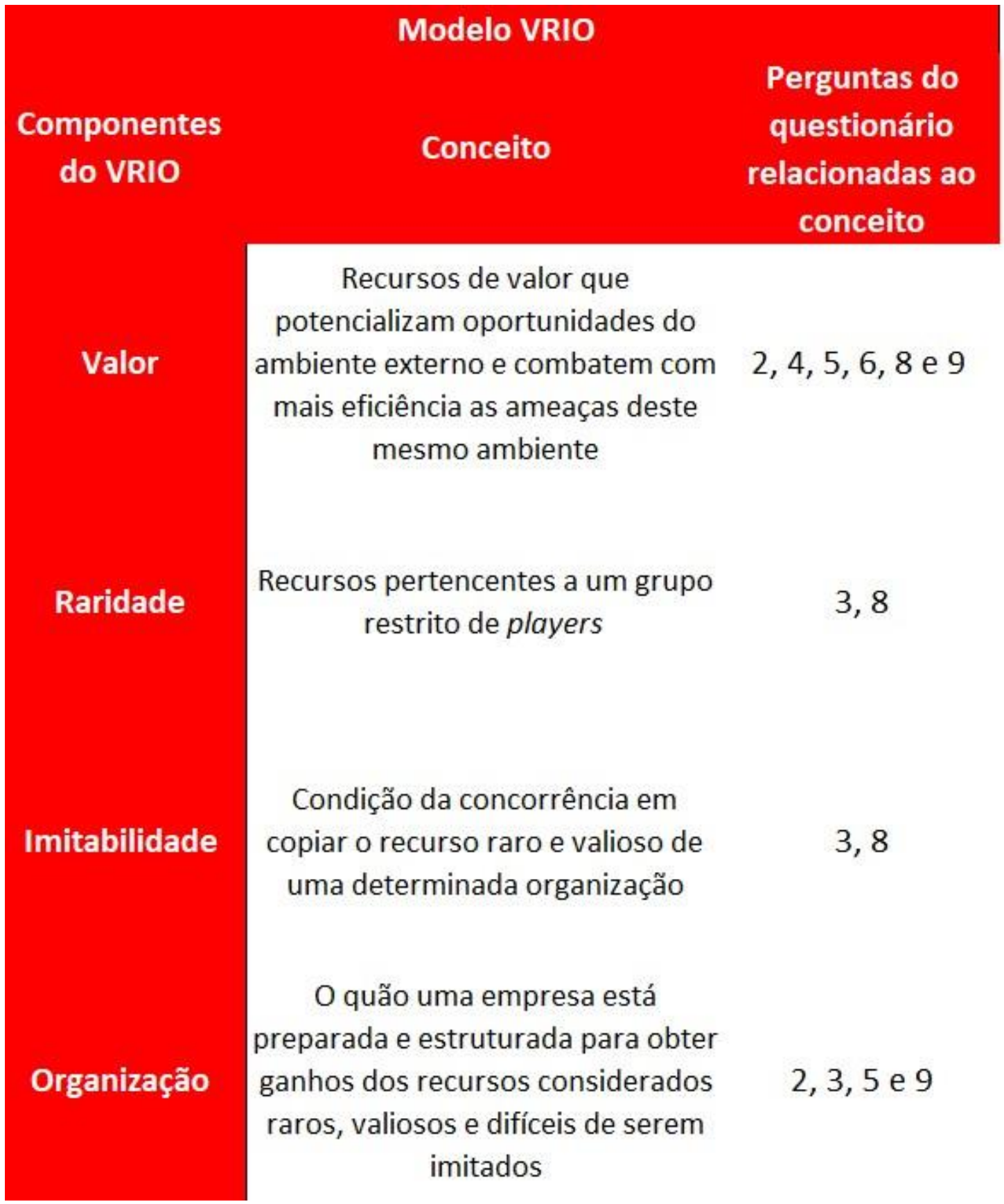

Fonte: elaboração própria

Para obter a conclusão de que o Blockchain, de fato, não gera vantagem competitiva sustentável, foram organizados, primeiramente, quadros com os entrevistados a respeito de suas respectivas avaliações, sintetizadas, quanto à classificação da tecnologia dentro do modelo VRIO: nesta etapa, seis dos oito participantes forneceram respostas completas sobre os quatro 
pontos do modelo. Num segundo momento, foi construído um quadro com o resumo destas respostas, apontando que implicações competitivas foram geradas. O resultado final apontou que, para quatro dos seis entrevistados (67\%), o cenário caracterizou-se como o de paridade; para os outros dois (33\%), o cenário apontou para uma implicação de vantagem temporária. As respostas, bem como as análises de cada participante e de suas avaliações quanto ao modelo VRIO, seguem abaixo:

Tabela 3 - Análise VRIO: Hélio Mosquim

\begin{tabular}{|c|c|c|}
\hline \multicolumn{3}{|c|}{$\begin{array}{c}\text { Entrevistado - Hélio Mosquim } \\
\text { Modelo VRIO }\end{array}$} \\
\hline $\begin{array}{c}\text { Componentes } \\
\text { do VRIO }\end{array}$ & $\begin{array}{l}\text { Perguntas do } \\
\text { questionário } \\
\text { relacionadas ao } \\
\text { conceito }\end{array}$ & Respostas \\
\hline Valor & $2,4,5,6,8$ e 9 & $\begin{array}{l}\text { Afirma a importância e a } \\
\text { oportunidade da tecnologia nos } \\
\text { serviços da Vale, cobrindo } \\
\text { deficiências do mercado. }\end{array}$ \\
\hline Raridade & 3,8 & $\begin{array}{l}\text { Não é raro: a Vale trabalha com } \\
\text { outras empresas. A tecnologia está } \\
\text { disponível entre os concorrentes e é } \\
\text { esperado que haja contribuição nas } \\
\text { cadeias de Supply Chain. }\end{array}$ \\
\hline Imitabilidade & 3,8 & $\begin{array}{c}\text { A imitação ocorre devido ao trabalho } \\
\text { cooperativo realizado com outros } \\
\text { players. }\end{array}$ \\
\hline Organização & $2,3,5$ e 9 & $\begin{array}{l}\text { Sim, a empresa explora e está } \\
\text { preparada para o uso da tecnologia. } \\
\text { Investimentos na infra-estrutura e } \\
\text { implementação da ferramenta são } \\
\text { constantes e tratados como } \\
\text { estratégicos. }\end{array}$ \\
\hline
\end{tabular}

Fonte: elaboração própria 
Tabela 4 - Análise VRIO: Leonardo Alexander

\begin{tabular}{|c|c|c|}
\hline \multirow{2}{*}{\multicolumn{3}{|c|}{$\begin{array}{c}\text { Entrevistado - Leonardo Alexander } \\
\text { Modelo VRIO }\end{array}$}} \\
\hline & & \\
\hline $\begin{array}{l}\text { Componentes } \\
\text { do VRIO }\end{array}$ & $\begin{array}{c}\text { Perguntas do } \\
\text { questionário } \\
\text { relacionadas ao } \\
\text { conceito }\end{array}$ & Respostas \\
\hline Valor & $2,4,5,6,8$ e 9 & $\begin{array}{l}\text { Destaca o nível de eficiência de } \\
\text { seus processos, muito por conta da } \\
\text { segurança e da validação de suas } \\
\text { operações com o Blockchain. }\end{array}$ \\
\hline Raridade & 3,8 & $\begin{array}{c}\text { Não, outras empresas têm acesso ao } \\
\text { recurso. }\end{array}$ \\
\hline Imitabilidade & 3,8 & $\begin{array}{l}\text { Pelo acesso que os concorrentes } \\
\text { têm, é possível de o uso da } \\
\text { ferramenta ser imitável. }\end{array}$ \\
\hline Organização & $2,3,5$ e 9 & $\begin{array}{l}\text { Afirma que sua empresa tem } \\
\text { maturidade organizacional para } \\
\text { utilizar a tecnologia }\end{array}$ \\
\hline
\end{tabular}

Fonte: elaboração própria 
Tabela 5 - Análise VRIO: Carlos Lessandro

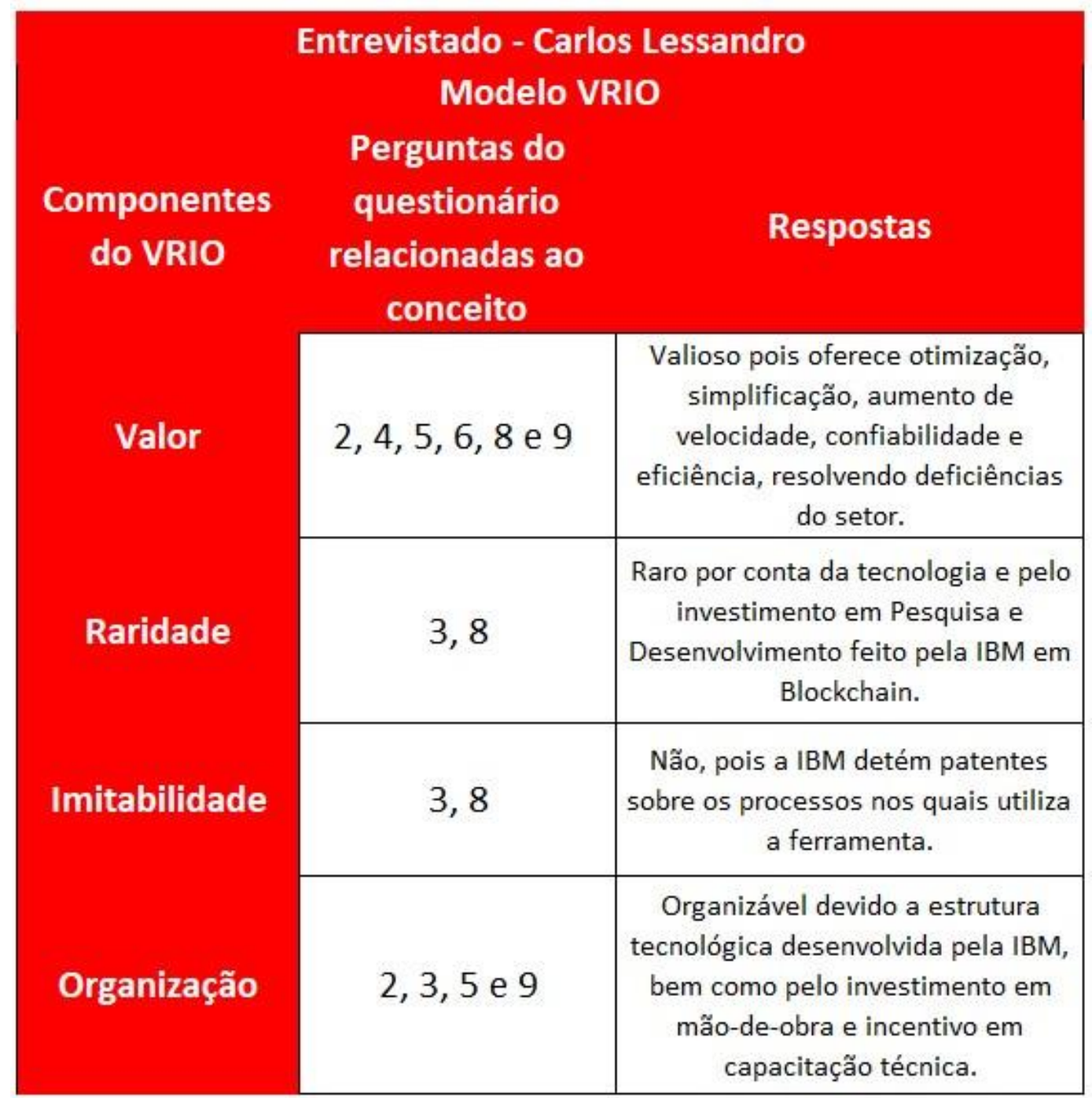

Fonte: elaboração própria 
Tabela 6 - Análise VRIO: Carlos Henrique

\begin{tabular}{|c|c|c|}
\hline \multirow{2}{*}{\multicolumn{3}{|c|}{$\begin{array}{c}\text { Entrevistado - Carlos Henrique } \\
\text { Modelo VRIO }\end{array}$}} \\
\hline & & \\
\hline $\begin{array}{l}\text { Componentes } \\
\text { do VRIO }\end{array}$ & $\begin{array}{c}\text { Perguntas do } \\
\text { questionário } \\
\text { relacionadas ao } \\
\text { conceito }\end{array}$ & Respostas \\
\hline Valor & $2,4,5,6,8$ e 9 & $\begin{array}{c}\text { Valioso por conta da sua } \\
\text { rastreabilidade, monitoramento e } \\
\text { diminuição de custos operacionais, } \\
\text { solucionando problemas da cadeia } \\
\text { que antes eram "invisíveis". }\end{array}$ \\
\hline Raridade & 3,8 & $\begin{array}{l}\text { Apesar de trabalhar com centenas } \\
\text { de empresas desenvolvendo o } \\
\text { Blockchain, é raro para a IBM por } \\
\text { conta do conhecimento da } \\
\text { tecnologia Hyperledger. }\end{array}$ \\
\hline Imitabilidade & 3,8 & $\begin{array}{c}\text { As patentes de processos protegem } \\
\text { as soluções desenvolvidas pela IBM, } \\
\text { impossibilitando a imitação das } \\
\text { mesmas. }\end{array}$ \\
\hline Organização & $2,3,5$ e 9 & $\begin{array}{l}\text { A IBM mostra-se organizável, tanto } \\
\text { por conta de sua natureza } \\
\text { tecnológica quanto pela sua visão } \\
\text { estratégica sobre o Blockchain. }\end{array}$ \\
\hline
\end{tabular}

Fonte: elaboração própria 
Tabela 7 - Análise VRIO: Reider Arnaud

\begin{tabular}{|c|c|c|}
\hline $\begin{array}{c}\text { Componentes } \\
\text { do VRIO }\end{array}$ & $\begin{array}{l}\text { Entrevistado - Re } \\
\text { Modelo V } \\
\text { Perguntas do } \\
\text { questionário } \\
\text { relacionadas ao } \\
\text { conceito }\end{array}$ & $\begin{array}{l}\text { der Arnaud } \\
\text { lo }\end{array}$ \\
\hline Valor & $2,4,5,6,8$ e 9 & $\begin{array}{l}\text { Indica que o grande valor da } \\
\text { ferramenta está na maior } \\
\text { transparência dos ativos nas } \\
\text { operações e na eliminação de } \\
\text { intermediários. }\end{array}$ \\
\hline Raridade & 3,8 & $\begin{array}{c}\text { Não é raro, pois o código pode ser } \\
\text { encontrado publicamente na } \\
\text { Ethereum. }\end{array}$ \\
\hline Imitabilidade & 3,8 & $\begin{array}{c}\text { Como o Ethereum é uma plataforma } \\
\text { pública, qualquer empresa que } \\
\text { tenha interesse pode investir nos } \\
\text { códigos de Blockchain }\end{array}$ \\
\hline Organização & $2,3,5$ e 9 & $\begin{array}{l}\text { O recurso é explorado pela sua } \\
\text { organização, uma vez que tem uma } \\
\text { startup voltada exclusivamente para } \\
\text { serviços de Blockchain. }\end{array}$ \\
\hline
\end{tabular}

Fonte: elaboração própria 
Tabela 18 - Análise VRIO: Eric Rossati

\begin{tabular}{|c|c|c|}
\hline \multicolumn{3}{|c|}{$\begin{array}{c}\text { Entrevistado - Eric Rossati } \\
\text { Modelo VRIO }\end{array}$} \\
\hline $\begin{array}{l}\text { Componentes } \\
\text { do VRIO }\end{array}$ & $\begin{array}{c}\text { Perguntas do } \\
\text { questionário } \\
\text { relacionadas ao } \\
\text { conceito }\end{array}$ & Respostas \\
\hline Valor & $2,4,5,6,8$ e 9 & $\begin{array}{l}\text { Aponta que a rastreablidade é um } \\
\text { dos maiores valores do Blockchain, } \\
\text { bem como a integração entre as } \\
\text { diversas soluções de sistemas ERP. }\end{array}$ \\
\hline Raridade & 3,8 & $\begin{array}{c}\text { Não é raro. Salienta que a SAP, como } \\
\text { maior provedora de ERPs do mundo, } \\
\text { será seguida por outras empresas no } \\
\text { que tange o uso do Blockchain. }\end{array}$ \\
\hline Imitabilidade & 3,8 & $\begin{array}{c}\text { Afirma que no curto/médio prazo as } \\
\text { empresas terão a possibilidade de } \\
\text { imitar as soluções, especialmente as } \\
\text { que fornecem ERPs. }\end{array}$ \\
\hline Organização & $2,3,5$ e 9 & $\begin{array}{l}\text { Assegura que a SAP, em breve, } \\
\text { implementará o Blockchain em seu } \\
\text { processo de compras e que a } \\
\text { empresa já tem a estrutura e capital } \\
\text { intelectual disponível para usar a } \\
\text { ferramenta. }\end{array}$ \\
\hline
\end{tabular}

Fonte: elaboração própria 
Tabela 9 - Análise VRIO: Resultado geral

\begin{tabular}{|c|c|c|c|c|c|}
\hline Entrevistado & $\begin{array}{c}\text { Recurso é } \\
\text { valioso? }\end{array}$ & $\begin{array}{c}\text { Recurso é } \\
\text { raro? }\end{array}$ & $\begin{array}{c}\text { É difícil de } \\
\text { imitar? }\end{array}$ & $\begin{array}{c}\text { A empresa } \\
\text { explora? }\end{array}$ & $\begin{array}{l}\text { Implicações } \\
\text { competitivas }\end{array}$ \\
\hline $\begin{array}{c}\text { Hélio } \\
\text { Mosquim }\end{array}$ & Sim & Não & - & Sim & Paridade \\
\hline $\begin{array}{l}\text { Leonardo } \\
\text { Alexander }\end{array}$ & Sim & Não & - & Sim & Paridade \\
\hline $\begin{array}{c}\text { Carlos } \\
\text { Lessandro }\end{array}$ & Sim & Sim & Não & Sim & $\begin{array}{l}\text { Vantagem } \\
\text { temporária }\end{array}$ \\
\hline $\begin{array}{c}\text { Carlos } \\
\text { Henrique }\end{array}$ & Sim & Sim & Não & Sim & $\begin{array}{l}\text { Vantagem } \\
\text { temporária }\end{array}$ \\
\hline $\begin{array}{l}\text { Reider } \\
\text { Arnaud }\end{array}$ & Sim & Não & - & Sim & Paridade \\
\hline Eric Rossati & Sim & Não & - & Sim & Paridade \\
\hline
\end{tabular}

Fonte: elaboração própria

Ao ser considerada a maioria dos respondentes, o diagnóstico configura, como preconizado por Barney e Hesterly (2007), a chamada Paridade Competitiva, presente explicitamente na fala de um dos entrevistados (Hélio Mosquim). As implicações econômicas são normais, caracterizando a necessidade de as organizações adotarem a tecnologia para manterem o mínimo possível de competitividade diante da concorrência: em não acontecendo a adoção, os níveis de competitividade decairão, possibilitando perdas sensíveis se comparado à empresas com a tecnologia já implementada. O Blockchain, neste estudo e de modo geral, surge como um recurso de força das empresas no mercado de logística e Supply chain. 
Contudo, é importante salientar que este é o cenário atual da ferramenta e sua empregabilidade no setor. Mesmo sendo imitável e não raro, o Blockchain pode ser atrelado a modelos de negócios disruptivos, especialmente se acoplado com outras tecnologias da Indústria 4.0, garantindo uma forte diferenciação entre os adotantes. Como recurso adotado sozinho, o Blockchain não se mostrou capaz, neste estudo, de ser um recurso de vantagem competitiva sustentável em supply chain para a maioria das empresas; porém, em contextos onde ele atue em modelagem de negócios, com ferramentas ágeis e com outras tecnologias, sua participação pode ser fundamental para gerar a vantagem competitiva sustentável. Vale ressaltar que este diagnóstico está voltado para empresas que usam a tecnologia como clientes finais: os prestadores de serviços, tais como a IBM, podem alcançar a vantagem competitiva sustentável com o recurso, mas isto não está atrelado obrigatoriamente e se, somente se, ao setor de supply chain. A ferramenta pode ser vantajosa competitivamente e sustentável para a IBM por outros motivos, não ligados necessariamente ao objeto de estudo desta monografia.

Levado em consideração todos estes pontos, ressalta-se a oportunidade que o Blockchain proporciona em melhorias de eficiência e produtividade nas atividades do setor estudado neste Trabalho de Conclusão de Curso: maior segurança, velocidade, rastreabilidade, solução de disputas, eliminação de intermediários, acompanhamento de pedidos em tempo real, fechamento digital de faturas antes feito manualmente e previsibilidade são alguns dos diversos ganhos que a aplicação já oferece para os seus adotantes, o que caracteriza um movimento de transformação digital bastante intenso e necessário para garantir, no mínimo, a sobrevivência dos negócios em um futuro bem próximo.

Desenvolver a capacidade de identificar forças em novas tecnologias, notadamente o Blockchain, será passo imperativo para as empresas que quiserem competir nos mercados globais. Notou-se no estudo comportamentos de rejeição e preconceito contra a ferramenta, quer seja pela mudança de cultura, quer seja pela desistência de modelos tradicionais de negócios que ainda oferecem determinado nível de familiaridade, ou até mesmo pela aversão a comandos digitais inovadores 
que exijam novas habilidades e reciclagens de certas profissões: tais comportamentos, no longo prazo, condenarão as organizações a crises cada vez mais consistentes e repetitivas, afetando a sua produção e, por fim, até mesmo sua viabilidade financeira e operacional.

O uso do Blockchain em supply chain já mostra-se atrativo, quando não obrigatório - como exposto nas entrevistas sobre a conexão com sistemas ERP - : empresas, profissionais e consumidores vão experimentar, num período de curto a médio prazo, mudanças na forma como consomem serviços e produtos, dando prosseguimento ao que se convencionou chamar de Quarta Revolução Industrial. Este panorama não tardará a criar novos modelos de negócios e novas formas de consumo, exigindo adaptabilidade e a cada vez mais constante busca por inovação por partes das organizações. Os insumos apresentados neste Trabalho de Conclusão de Curso visam a possibilidade de oferecer aos profissionais de administração, de logística e os que trabalham com gestão de processos de cadeias de suprimentos, uma maior compreensão sobre as barreiras, oportunidades e benefícios que o Blockchain carrega consigo quando da sua implementação em fluxos de informações, serviços e produtos transacionados globalmente.

\subsection{Recomendações para novos estudos}

O atual quadro da pandemia certamente pode gerar ruídos quanto a alguns cenários apresentados no ano de 2020 e que, nos anos seguintes, podem desaparecer. Por conta disso, um novo estudo, em especial no médio prazo e depois de um programa universal de vacinação contra o coronavirus, pode ser interessante de ser realizado, até mesmo para confirmar - ou não - as projeções e indicadores de consultorias sobre o desenho formado no presente ano quanto ao emprego do Blockchain. Ao mesmo tempo em que pode haver contenção de despesas e custos com a ferramenta, pode haver também oportunidades e modelos de negócios surgindo ao longo dos próximos meses. Processos digitais serão acelerados conforme necessidade de trabalho home-office e entrega de produtos via postagem, por exemplo: o volume de necessidades dessa 
natureza certamente influenciará como o Blockchain será visto daqui para a frente.

O Blockchain é apenas uma das tecnologias da Indústria 4.0 que pode trazer maior eficiência e produtividade para supply chain. Convém, então, o estudo de como outras ferramentas - IoT, Big Data e Machine Learning, por exemplo - atreladas ao Blockchain, afetariam as cadeias globais de suprimentos. O estudo mais detalhado de cada uma dessas ferramentas e da sinergia delas em uma solução voltada para supply chain certamente encontrará campos de maior aprofundamento e, possivelmente, de aplicabilidade, tanto na academia quanto no mercado.

O presente estudo versou mais sobre as condições de gerenciamento e administração da ferramenta do que propriamente o seu conteúdo técnico, ao menos não tão profundamente técnico. Uma parceria entre os departamentos de administração e informática, de modo a realizar um trabalho em conjunto e que abarque tanto o lado técnico quando o lado de gerenciamento, também é uma oportunidade de aprofundar e disseminar o conhecimento. Por fim, poderia ser interessante a viabilidade de um estudo quantitativo sobre o tema, elencando numericamente $\mathrm{e}$ dando embasamento matemático a fatores que, dentro de um estudo qualitativo, não são tão aproveitados ou não são objeto de estudo. 


\section{Bibliografia}

ABRALOG (São Paulo). Abralog mostra como Blockchain conecta logística em tempo real. Abralog. 2018. Disponível em: <https://www.abralog.com.br/noticias/blockchain-conecta-toda-a-cadeialogistica-em-tempo-real/>. Acesso em: 25 set. 2020.

ANDREWS, Kenneth R. The concept of corporate strategy. Homewood, III.: Dow Jones Irwin. 2017.

AQUINO, Magali. Adoção de blockchain na gestão de cadeias de suprimentos do Brasil. 2019. 86 f. Dissertação (Mestrado) - Curso de Administração, Fundação Getulio Vargas, São Paulo, 2019.

BADZAR, Amina. Blockchain for securing sustainable transport contracts and supply chain transparency. Master's Study, Lund University, Helsingborg, Sweden, 2016.

BARNEY, Jay. Firm resources and sustained competitive advantage. Journal of management, v. 17, n. 1, p. 99-120, 1991.

BARNEY, Jay; HESTERLY, William S.; ROSEMBERG, Monica. Administração estratégica e vantagem competitiva. Pearson Educación, 2007.

BIANCOLINO, César Augusto; MACCARI, Emerson Antonio; PEREIRA, Maurício Fernandes. A inovação como instrumento de geração de valor ao setor de serviços em TI. Revista Brasileira de Gestão de Negócios, v. 15, n. 48, p. 410-426, 2013. 
CARVALHO, José Meixa Crespo de (2002). Logistica $3^{\circ}$ ed. Lisboa: Edições Sílabo

CHANDLER JR, Alfred D. Strategy and Structure: Chapters in the History of the Industrial Empire. Cambridge, Mass.: M. I. T. Press. Pp. xiv, 463. 1962.

CHESBROUGH, Henry William. Open innovation: The new imperative for creating and profiting from technology. Harvard Business Press, 2003.

CORREIA, Adriano; TIPPING, Andrew; BAUMEISTER, Dominik; KLETZEL, Jonathan; KAUSCHKE, Peter. Transportation and logistics trends 2019: The logistics segment confronts an onslaught of startups. Part of PwC's 22nd Annual Global CEO Survey trends series. London, n. 22 p. 112, 2019.

COSTA, Machado da. BRF e Carrefour usam tecnologia do Bitcoin para rastrear alimentos. Istoé Dinheiro. 2017. Disponível em: https://www.istoedinheiro.com.br/brf-e-carrefour-usam-tecnologia-dobitcoin-para-rastrear-alimentos/. Acesso em: 10 set. 2020.

CROSBY, Michael et al. Blockchain technology: Beyond bitcoin. Applied Innovation, v. 2, n. 6-10, p. 71, 2016.

FINKELSTEIN, Joseph; NEWMAN, David. The third industrial revolution: a special challenge to managers. Organizational Dynamics, v. 13, n. 1, p. 53-65, 1984.

GOBBLE, MaryAnne M. Charting the innovation ecosystem. ResearchTechnology Management, v. 57, n. 4, p. 55-59, 2014.

GODOY, Arilda Schmidt. A pesquisa qualitativa e sua utilização em administração de empresas. Rev. adm. empres, p. 65-71, 1995. 
GOVINDARAJAN, Vijay. The three-box solution: A strategy for leading innovation. Harvard Business Review Press. 2016

GREGORIO, Rafael. Criptomoedas e blockchain: um 2019 agitado e o que esperar para 2020. Valor Investe. 2020. Disponível em: <https://valorinveste.globo.com/mercados/cripto/noticia/2020/01/07/cripto moedas-e-blockchain-um-2019-agitado-e-o-que-esperar-para2020.ghtml>. Acesso em: 03 set. 2020.

HANSEN, Morten T.; BIRKINSHAW, Julian. The innovation value chain. Harvard business review, v. 85, n. 6, p. 121, 2007.

IBM (São Paulo). Portos da América Latina integram plataforma Blockchain da IBM e Maersk para impulsionar participação no comércio global. IBM. 2019. Disponível em: <https://www.ibm.com/blogs/ibm-comunica/portosda-america-latina-integram-plataforma-blockchain-da-ibm-e-maersk-paraimpulsionar-participacao-no-comercio-global/>. Acesso em: 27 out. 2020.

INTELIPOST (São Paulo). A tecnologia Blockchain e seu impacto na cadeia logística. Intelipost. 2017. Disponível em: $<$ https://www.intelipost.com.br/blog/a-tecnologia-blockchain-e-seuimpacto-na-cadeia-logistica/>. Acesso em: 23 set. 2020.

IRANNEZHAD, Elnaz. Is blockchain a solution for logistics and freight transportation problems? Transportation Research Procedia, v. 48, p. 290-306, 2020.

IMERI, A., KHADRAOUI, D, AGOULMINE N. Blockchain for solving the security and trust issues in supply chain management and logistics: a survey. In Engineering Digital Transformation. Springer. 2018. 
KIRCHMER, Mathias. Innovation: An Important Goal of MPE. High Performance Through Process Excellence: From Strategy to Operations, p. 21-35, 2009.

KOZLENKOVA, Irina V. et al. The role of marketing channels in supply chain management. Journal of Retailing, v. 91, n. 4, p. 586-609, 2015.

LAMBERT, Douglas M.; COOPER, Martha C.; PAGH, Janus D. Supply chain management: implementation issues and research opportunities. The international journal of logistics management, v. 9, n. 2, p. 1-20, 1998.

LEE, Sang M.; OLSON, David L.; TRIMI, Silvana. Co-innovation: convergenomics, collaboration, and co-creation for organizational values. Management decision, 2012.

LEE, Sang M.; OLSON, David Louis. Convergenomics: strategic innovation in the convergence era. Gower Publishing, Ltd., 2010.

LEE, Sang M.; TRIMI, Silvana. Innovation for creating a smart future. Journal of Innovation \& Knowledge, v. 3, n. 1, p. 1-8, 2018.

LIEBER, A. Trust in Trade: Announcing a new blockchain partner. IBM. 2017.

MENTZER et al. Defining supply chain management. Journal of Business logistics, v. 22, n. 2, p. 1-25, 2001.

MEYER, John P.; ALLEN, Natalie J. A three-component conceptualization of organizational commitment. Human resource management review, $v$. 1, n. 1, p. 61-89, 1991.

MORABITO, Vincenzo. Business Innovation Through Blockchain - The B $^{3}$ Perspective. Milan: Springer, 2017. 
NAKAMOTO, Satoshi; BITCOIN, A. A peer-to-peer electronic cash system. Bitcoin. v. 4, 2008.

OECD, TEP. Technology and the economy: the key relationships. Technology/Economy Programme, 1992

ØLNES, Svein; UBACHT, Jolien; JANSSEN, Marijn. Blockchain in government: Benefits and implications of distributed ledger technology for information sharing. 2017

PAVÃO, Yeda Maria Pereira; SEHNEM, Simone; HOFFMANN, Valmir Emil. Análise dos recursos organizacionais que sustentam a vantagem competitiva. Revista de Administração, v. 46, n. 3, p. 228-242, 2011.

PAWCZUK, Linda et al. Deloitte's 2020 Global Blockchain Survey. New York: Deloitte, 2020. 37 p.

PENROSE, Edith Elura Tilton. The theory of the growth of the firm. Oxford: Blackwell, 1959.

PILAV-VELIĆ, Amila; MARJANOVIC, Olivera. Integrating open innovation and business process innovation: Insights from a largescale study on a transition economy. Information \& Management, v. 53, n. 3, p. 398-408, 2016.

PORTER, Michael E. Estratégia competitiva. Rio de Janeiro: Campus, 1983.

PWC. Five Forces Transforming Transport \& Logistics: PwC CEE Transport \& Logistics Trend Book 2019.

RAMASWAMY, Venkat; OZCAN, Kerimcan. The co-creation paradigm. Stanford University Press, 2014. 
SALANCIK, Gerald R.; PFEFFER, Jeffrey. A social information processing approach to job attitudes and task design. Administrative science quarterly, p. 224-253, 1978.

SCHUMPETER, Joseph Alois. Teoria do desenvolvimento econômico: uma investigação sobre lucros, capital, crédito, juro e o ciclo econômico (1934). Tradução de Maria Sílvia Possas. Coleção Os Economistas. São Paulo: Nova Cultural, 1997.

SCHWAB, Klaus. The Fourth Industrial Revolution: what it means, how to respond. 2016.

SEHNEM, Simone; LAZZAROTTI, Fábio; BANDEIRA-DE-MELLO, Rodrigo. $O$ impacto porteriano, iniciado há 30 anos, chegou ao final do seu curso? Um estudo sobre o emprego do paradigma de Porter no Brasil. In: ENCONTRO DE ESTUDOS EM ESTRATÉGIA (3Es), 4., 2009, Recife. Anais. Rio de Janeiro: Anpad, 2009. v.1. p.1-16.

SIVULA, Ari; SHAMSUZZOHA, Ahm; HELO, Petri. Blockchain in logistics: mapping the opportunities in con-struction industry. In: International Conference on Industrial Engineering and Operations Management. 2018.

SOLLEIRO, José Luis; CASTAÑÓN, Rosario. Competitiveness and innovation systems: the challenges for Mexico's insertion in the global context. Technovation, v. 25, n. 9, p. 1059-1070, 2005.

TAPSCOTT, Don; WILLIAMS, Anthony D. Wikinomics: How mass collaboration changes everything. Penguin, 2008.

ULRICH, David; BARNEY, Jay B. Perspectives in organizations: resource dependence, efficiency, and population. Academy of Management Review, v. 9, n. 3, p. 471-481, 1984. 
WALPORT, MGCSA et al. Distributed ledger technology: Beyond blockchain. UK Government Office for Science, v. 1, p. 1-88, 2016.

WERNERFELT, Birger. A resource-based view of the firm. Strategic Management Journal, Chicago, v.5, n.2, p.171-180, Apr./June 1984.

WILLIAMS, Reid. How Bitcoin's Technology Could Make Supply Chains More Transparent. Coindesk. v. 23, p. 2018, 2015.

WORLD BANK. Gross domestic product (2019). The World Bank. 2019.

World Economic Forum. Deep Shift Technology Tipping Points and Societal Impact. Geneva: World Economic Forum, 2015. 44 p.

WU, Hanqing et al. Data management in supply chain using blockchain: Challenges and a case study. In: 2019 28th International Conference on Computer Communication and Networks (ICCCN). IEEE, 2019. p. 1-8.

ZHENG, Zibin et al. An overview of blockchain technology: Architecture, consensus, and future trends. In: 2017 IEEE international congress on big data (BigData congress). IEEE, 2017. p. 557-564. 


\section{APÊNDICE 1}

\section{Roteiro da entrevista}

Questão-chave:

Há projetos envolvendo o Blockchain (ou expectativa de) na área de Supply Chain em sua empresa?

\section{Bloco I - Função do entrevistado}

1. Qual seu cargo na sua empresa? Se atua com Supply Chain, em quais áreas você possui responsabilidade?

- Planejamento de Demanda;

- Movimentação de Materiais e Armazenagem (de insumos e produtos acabados);

- Compras;

- Importação e Exportação;

- Logística de Distribuição;

- Transporte;

- Outra? Qual? 


\section{Bloco II - Blockchain na operação}

2. Como a tecnologia funcionaria/ funciona nas operações de Supply Chain sob sua responsabilidade?

3. O Blockchain será/foi desenvolvido apenas pela empresa? Quais áreas? Houve/haverá alguma parceria externa com outras empresas? (como, por exemplo, projetos de código aberto ou criação de ecossistemas)?

4. Quais os principais objetivos que o Blockchain trará/trouxe para as operações de cadeia de Suprimentos?

5. Quais são as barreiras mais difíceis de serem superadas quanto à implementação da tecnologia? E as maiores oportunidades? (mão-de-obra qualificada, dificuldade de aprendizado, problemas técnicos, infraestrutura deficitária)

\section{Bloco III - Feedbacks e projeção de investimentos}

6. Há feedback trazido pelos stakeholders quanto aos resultados obtidos pósefetivação da tecnologia em seus processos? (pergunta apenas para quem já tenha implementado a tecnologia)

7. Na sua visão, qual poderia ser o valor investido na área nos próximos anos? (caso o valor nominal seja um dado sigiloso, pode ao menos citar uma proporção de investimentos - quantos \% em casa ano, se pretende dobrar, triplicar, quadruplicar investimentos?)

\section{Bloco IV - Estratégia no setor de Supply Chain}

8. Como você avaliaria a possibilidade de o emprego do blockchain permitir uma diferenciação da sua empresa diante da concorrência (qual seria a geração de valor)? Seria difícil copiar a tecnologia ou sua aplicação?

9. Como a utilização do Blockchain aumentou/aumentaria o nível de eficiência/produtividade dos processos em sua área? 
10. Como a pandemia afetou a estratégia de utilização do Blockchain na área de Supply Chain?

Gostaria de fazer algum comentário complementar? 